Article

\title{
Regional Differences in Energy and Environmental Performance: An Empirical Study of 283 Cities in China
}

\author{
Zuoren Sun ${ }^{1, *}$, Chao An ${ }^{1}$ and Huachen Sun ${ }^{2, *}$ \\ 1 Business School, Shandong University, Weihai, No. 180 West Culture Road, Weihai 264209, China; \\ anchao0911@163.com \\ 2 Shandong Academy of Macroeconomic Research, No. 9 South Qianfoshan Road, Jinan 250014, China \\ * Correspondence: sunzuoren@sdu.edu.cn (Z.S.); shc82623598@126.com (H.S.)
}

Received: 4 June 2018; Accepted: 29 June 2018; Published: 3 July 2018

\begin{abstract}
This paper proposes a new non-radial biennial Luenberger energy and environmental performance index (EEPI) to measure the energy and environmental performance (EEP) change in various Chinese cities. The sources of EEP change, in terms of technical efficiency change and technological change, are examined by Luenberger EEPI. The contributions from specific undesirable outputs and energy inputs to the EEP change are identified by means of the non-radial efficiency measure. The proposed approach is applied to evaluate the EEP of the industrial sector in 283 cities in China over 2010-2014. Factors influencing the emission abatement potential are investigated by employing geographically weighted regression (GWR) model. We find that (1) changes in EEP can be attributed to technological progress but that technological progress slows down across the study period; (2) the soot emission performance experiences a downtrend among four specific sub-performances (i.e., energy, wastewater, $\mathrm{SO}_{2}$ and soot performances) in line with the truth that severe haze happened frequently in China; (3) the best performers begin to move from the coastal to inland cities with the less resource consumption and higher ecological quality; (4) cities with the strongest positive effect in regards to pollution intensity on emission abatement potential are located in the areas around the Bohai Gulf, where air pollution is particularly severe.
\end{abstract}

Keywords: data envelopment analysis; biennial Luenberger index; geographically weighted regression; EEP

\section{Introduction}

With globalization, China has accelerated melting into the world economy after entering World Trade Organization (WTO) and has become a world factory in international division with rapid economic growth. However, this growth is mainly driven by development within the energy-intensive industrial sector [1]. According to the British Peroleum (BP) Statistical Review of World Energy 2017 [2], China is currently the world's largest energy consumer at $23 \%$ of the total global consumption and $27 \%$ of the demand growth of global energy consumption in 2016. However, China has paid a high price to the environment for such rapid advancement. Uncontrolled fossil fuel combustion has released harmful substances in various forms and led to all kinds of pollutions [3], e.g., water contamination, acid rain, and haze (smog). Large loads of waste gases have been emitted into the atmosphere to create a severe decline in air quality.

China has suffered from a severe haze over many of its cities comprised of fine particulate matter less than 2.5 micrometers in diameter $\left(\mathrm{PM}_{2.5}\right)$, especially in winter months, since 2013 [4,5]. In 2016, only 84 Chinese cities had standard air quality-this amounts to merely $24.9 \%$ among the 338 monitored cities at or above the prefecture level (Report on the State of China's Environment in 2016 [6]). Pollution severely affects Chinese citizens' daily living conditions and, ultimately, threatens their 
health. Epidemiological studies have revealed a strong association between exposure to fine particulate matter and mortality [7,8]. Many environmental laws and regulations have been enacted to combat this, including China's State Council's Action Plan for Air Pollution Prevention and Control (One could refer to http://www.gov.cn/zwgk/2013-09/12/content_2486773.htm for more details.) targeting air quality in September 2013. One goal of the Action Plan is to reduce the average concentration of fine particulate matter by $25 \%$ in the Beijing-Tianjin-Hebei region by 2017 against the 2012 level $\left(80 \mu \mathrm{g} / \mathrm{m}^{3}\right)$. Measuring energy efficiency and environmental efficiency can provide quantitative information for energy and environmental policy analysis and decision-making. Cities are not only places of high energy consumption, but also form the main sources of various pollutants. Cities, to this effect, are the main area for controlling pollutant emissions. It is essential for administrators to understand the energy and environmental performance (EEP) of their cities to formulate scientific, strategic goals for energy conservation and emission reduction.

In recent years, the data envelopment analysis (DEA) linear programming method has become a popular approach to measuring energy and environmental efficiency to reduce energy consumption and control emissions. DEA was proposed by Farrell [9] and developed by Charnes, et al. [10] to automatically generate appropriate production functions to combine multiple inputs and multiple outputs. The principle of DEA is to enable data to "speak for itself" rather than require excessive artificial parametric assumptions for functions [11]. With this approach, we only need to collect the values of variables for inputs and outputs to establish production frontiers without priori assumptions for functional forms. The automatically generated production frontiers make it possible to measure the distance from an observed decision-making unit (DMU) to projected production frontier, which determined by the efficient DMUs and with which the distance is defined as inefficiency measurement. Therefore, this advantage provides a simple way to measure the inefficiency of DMUs (i.e., ones which are under the production frontier) through measuring its distance to the referred production frontier. Many previous researchers have studied energy efficiency; Hu and Wang [12], for example, first established the total factor energy efficiency (TFEE) concept by using DEA. Song, et al. [13] used a bootstrap-DEA approach to find that China's energy efficiency has maintained a slow upward trend from 1992 to 2010. Özkara and Atak [14], and later Feng and Wang [15], measured total-factor energy efficiency and energy savings potential in Turkey's manufacturing industry and China's provincial industrial sectors, respectively. Zhou, et al. [16] proposed an output-specific energy efficiency estimating method. These researchers concentrated on static analysis without dynamic comparison. Honma and $\mathrm{Hu}$ [17] investigated the dynamic changes in energy efficiency by introducing a Malmquist productivity index (MPI). Other researchers, such as Wang and Zhou [18], Chang and $\mathrm{Hu}$ [19], and Zhang, et al. [20] have made dynamic analyses of energy efficiency as well.

Beside above energy efficiency evaluation models, researchers focused on securing as many desirable outputs as possible while minimizing the undesirable outputs which are inevitably produced by industrial production. Färe, et al. [21] first proposed the concept of environmental DEA technology to incorporate undesirable outputs into efficiency evaluation frameworks. Kuosmanen and Kortelainen [11] applied DEA to aggregate multiple undesirable outputs and emphasized the trade-off between economic production and environmental protection in regards to the impact of undesirable outputs on the economy. Kortelainen [22] extended the static framework to a dynamic environmental performance analysis by using MPI; they decomposed the changes in environmental performance into two components: relative environmental efficiency change and relative environmental technological change.

Many previous researchers have used the radial DEA approach to measure environmental performance, where different undesirable outputs are adjusted by the same proportion. However, radial efficiency measures overestimate technical efficiency due to the existence of nonzero slacks. A series of non-radial DEA models have been developed to resolve this limitation. For example, Zhou, et al. [23] employed a non-radial DEA approach to measure the environmental performance of OECD countries. Zhang and Choi [24] explored total-factor carbon emission performance 
in China's fossil fuel power plants using a metafrontier non-radial MPI. Rashidi and Saen [25] calculated the pure eco-efficiency of OECD countries by a non-radial DEA model based on green indicators. Sueyoshi and Goto [26] applied a non-radial DEA environmental assessment to evaluate the performance of coal-fired power plants in the northeast United States. Xie, et al. [27] computed environmental efficiency based on a directional distance function with the radial and non-radial slacks of outputs.

There are two major approaches to estimating productivity or efficiency changes: the Malmquist productivity index and Luenberger productivity index. Some researchers assert that the Malmquist productivity index overestimates productivity changes compared to the Luenberger $[28,29]$. Further, the Luenberger productivity index is a difference-based index, so it is well applicable to measuring differences in EEP. Recent researchers have adapted the Luenberger productivity index to study dynamic changes in productivity or efficiency. For instance, Mahlberg and Sahoo [30] applied non-radial decompositions of the Luenberger productivity index to analyze the eco-productivity performance behavior in 22 OECD countries. Based on a Luenberger environmental index, Azad and Ancev [31] measured the relative environmental efficiency of agricultural water use to reveal substantial variations across different regions. Wang [32] applied the Luenberger index to explore changes in energy and environmental productivity at the provincial level. Our research team developed a non-radial Luenberger productivity index to resolve the limitation of radial measurement [33,34]. Non-radial efficiency measures can help us identify specific effects and contributions of energy factor and specific undesirable outputs, while radial efficiency measures do not reflect the impact of emission structures on efficiency changes.

The aforementioned studies focused on single aspects of energy efficiency or environmental performance rather than integrated EEP measurements. A few researchers have investigated the integrated EEP by new DEA models. Wang, et al. [35], for example, used DEA window analysis to find that EEP is highest in the eastern area of China compared to other regions. Zhou and Wang [36] explored the energy and $\mathrm{CO}_{2}$ emission performance for over 100 countries by using a new directional distance function (DDF). Zhou, et al. [37], Vlontzos, et al. [38], Meng, et al. [39], Geng, et al. [40], Wang and Zhao [41], and Perez, et al. [42] measured integrated EEP in their respective studies. The researchers mentioned above have tended to focus on the regional or national level and lack of research down to the city level, though cities play an important role in environmental governance. Cities are responsible for $75-80 \%$ of global greenhouse emissions [43,44]. Only a few researchers, e.g., Li, et al. [45], Yuan, et al. [46], Wang, et al. [47], Zhou, et al. [48], and Guo, et al. [49] have explored environmental performance at the city level.

In the present study, we extended the existing research in two main aspects. In terms of methodology, we proposed an additive DEA model combined with a slack-based measure and non-radial directional distance function as first developed by Färe and Grosskopf [50]. The Luenberger productivity index with an additive structure is used to measure changes in productivity (which differs from the Malmquist index with multiplicative structure). We established a biennial Luenberger index extended from biennial Malmquist index proposed by Pastor, et al. [51] to avoid infeasible solution of DEA. In terms of indicator selection, we properly account for multi-undesirable outputs and compare these sub-performances. We also use the natural breaks method [52] to identify break points by picking the class breaks which maintain the greatest similarity in one class but maximize the difference among different classes. Geographical location has a marked effect on the emission abatement potential, so we alter the traditional regression to geographically weighted regression (GWR) to allow our estimated coefficients of influencing factors to vary by location.

The current our study is different from that of Picazotadeo, et al. [53], which focused on ecological-economic performance based on the Pressure Generating Technology (PGT) rather than environmental production technology. The current our study also differs from that of Wang and Wei [33], which explored the energy and environmental productivity change at the provincial-level by using Luenberger index and decomposed the energy and environmental 
productivity into four sub-indicators: Luenberger pure efficiency change, scale efficiency change, pure change in technology and change in returns to scale of technology. They analyzed energy input-specific and environmental productivity change without taking the undesirable output-specific performance into consideration. The current our study also differs from that of Zhou, Wang, Su, Zhou and Yao [48], which studied the change of industrial energy conservation and emission reduction according to the Malmquist index and only considered one undesirable output $\left(\mathrm{CO}_{2}\right)$. The three aforementioned research teams may not avoid infeasible solution of DEA when dealing with inter-temporal data. Our study first attempted to analyze undesirable outputs and energy inputs performances at the city level in China with a biennial Luenberger index to avoid infeasibility. The remainder of this paper is organized as follows. Section 2 presents the non-radial DEA model, decomposition method, and GWR estimation. Section 3 explains our data sources and presents our results with discussion. Section 4 summarizes our main conclusions and makes policy recommendations based on empirical results.

\section{Methodology}

\subsection{Biennial Energy and Environmental Production Technology}

Consider a production process with the vectors of non-energy inputs $(\mathbf{x})$, such as labor and capital input, and the vectors of energy inputs (e) to produce the vectors of desirable outputs $(\mathbf{y})$ and undesirable outputs $(\mathbf{b})$. The corresponding production set, called the energy and environmental production technology set, is:

$$
\mathbf{T}=\{(\mathbf{x}, \mathbf{e}, \mathbf{y}, \mathbf{b}):(\mathbf{x}, \mathbf{e}) \text { can produce }(\mathbf{y}, \mathbf{b})\}
$$

In the energy and environmental production technology set $\mathbf{T}$, inputs and desirable outputs are assumed to be strongly disposable. $\mathbf{T}$ satisfies two additional assumptions proposed by Färe, Grosskopf, Lovell and Pasurka [21] to model a production technology that includes both desirable and undesirable outputs.

(1) Weak disposability assumption: If $(\mathbf{x}, \mathbf{e}, \mathbf{y}, \mathbf{b}) \in \mathbf{T}$ and $0 \leq \theta \leq 1$, then $(\mathbf{x}, \mathbf{e}, \theta \mathbf{y}, \theta \mathbf{b}) \in \mathbf{T}$. It means that we can not reduce undesirable outputs alone while keeping the desirable outputs constant. In practice, it is feasible to reduce the desirable outputs and undesirable outputs at the same time; undesirable outputs can be abated at the cost of a decrease in desirable output.

(2) Null-jointness assumption: If $(\mathbf{x}, \mathbf{e}, \mathbf{y}, \mathbf{b}) \in \mathbf{T}$ and $\mathbf{b}=\mathbf{0}$, then $\mathbf{y}=\mathbf{0}$. Production must cease entirely in order to fully eliminate undesirable outputs.

It is unlikely to find a concrete production function which depicts the energy and environmental production technology set $\mathbf{T}$. Here, we use nonparametric DEA technology to approximately represent $\mathrm{T}$ with piecewise linear combinations of the observed data. On the assumption of constant returns to scale (CRS), the energy and environmental production technology $\mathbf{T}$ can be estimated as follows:

$$
\begin{aligned}
\hat{\mathbf{T}}=\{(\mathbf{x}, \mathbf{e}, \mathbf{y}, \mathbf{b}): & \sum_{k=1}^{K} \lambda_{k} x_{m k} \leq x_{m o}, m=1,2, \cdots, M ; \\
& \sum_{k=1}^{K} \lambda_{k} y_{n k} \geq y_{n o}, n=1,2, \cdots, N ; \lambda_{k} e_{q k} \leq e_{q 0}, \quad q=1,2, \cdots, Q \\
& \left.\lambda_{k} \geq 0, k=1,2, \cdots, K\right\}
\end{aligned}
$$

where $\lambda_{k}$ is the intensity variable that ensures the technology set $\mathbf{T}$ is bounded and closed. The first three inequality constraints indicate the strong disposability on inputs and desirable outputs (strong disposability means that increasing input will not decrease the output). To ensure technology set $\mathbf{T}$ satisfies the weak disposability and null-jointness assumptions, the equality constraint is imposed on undesirable outputs.

Technology is generally stable in the short run, so we neglect technological changes from period " $t$ " to " $t+1$ ", and combine technology set $\mathbf{T}^{\mathbf{t}}$ and $\mathbf{T}^{\mathbf{t}+1}$ together as $\mathbf{T}^{\mathbf{B}}=\mathbf{T}^{\mathbf{t}} \cup \mathbf{T}^{\mathbf{t}+1}$, namely, 
biennial energy and environmental technology, which represents the comprehensive technology shared by periods " $t$ " and " $t+1$ ". In order to estimate $\mathbf{T}^{\mathbf{B}}$, we use observations from periods " $t$ " and " $t+1$ " to construct the biennial energy and environmental DEA technology $\hat{\mathbf{T}}^{\mathbf{B}}$ as-formed by following linear constraints:

$$
\begin{aligned}
\hat{\mathbf{T}}^{\mathbf{B}}=\{(\mathbf{x}, \mathbf{e}, \mathbf{y}, \mathbf{b}): & \sum_{k=1}^{K} \lambda_{k}^{t+1} x_{m k}^{t+1}+\sum_{k=1}^{K} \lambda_{k}^{t} x_{m k}^{t} \leq x_{m o} m=1,2, \cdots, M \\
& \sum_{k=1}^{K} \lambda_{k}^{t+1} e_{q k}^{t+1}+\sum_{k=1}^{K} \lambda_{k}^{t} e_{q k}^{t} \leq e_{q o} q=1,2, \cdots, Q \\
& \sum_{k=1}^{K} \lambda_{k}^{t+1} y_{n k}^{t+1}+\sum_{k=1}^{K} \lambda_{k}^{t} y_{n k}^{t} \geq y_{n o} n=1,2, \cdots, N \\
& \sum_{k=1}^{K} \lambda_{k}^{t+1} b_{j k}^{t+1}+\sum_{k=1}^{K} \lambda_{k}^{t} b_{j k}^{t}=b_{j o} j=1,2, \cdots, J \\
& \lambda_{k}^{t} \geq 0 ; \lambda_{k}^{t+1} \geq 0 ; k=1,2, \cdots, K
\end{aligned}
$$

Model (3) can avoid infeasible solutions to the DEA model when dealing with cross-period data. Based on $\hat{\mathbf{T}}^{\mathbf{B}}$, we propose a biennial Luenberger productivity index derived from the concept of the biennial Malmquist productivity index [51].

\subsection{Biennial Luenberger Energy and Environmental Performance Index}

The Luenberger productivity index deduced by directional distance function (DDF) was first proposed by Chambers, et al. [54]. The DDF allowing the simultaneous evaluation of input contractions and output expansions can be defined as:

$$
\vec{D}\left[\mathbf{x}, \mathbf{e}, \mathbf{y}, \mathbf{b} ; \mathbf{g}=\left(-\mathbf{g}_{\mathbf{x}},-\mathbf{g}_{\mathbf{e}}, \mathbf{g}_{\mathbf{y}},-\mathbf{g}_{\mathbf{b}}\right)\right]=\sup \left[\beta \mid\left(\mathbf{x}-\beta \mathbf{g}_{\mathbf{x}}, \mathbf{e}-\beta \mathbf{g}_{\mathbf{e}}, \mathbf{y}+\beta \mathbf{g}_{\mathbf{y}}, \mathbf{b}-\beta \mathbf{g}_{\mathbf{b}}\right) \in \mathbf{T}\right]
$$

where $\mathbf{g}=\left(-\mathbf{g}_{\mathbf{x}},-\mathbf{g}_{\mathbf{e}}, \mathbf{g}_{\mathbf{y}},-\mathbf{g}_{\mathbf{b}}\right)$ is the directional vector.

Based on the Luenberger productivity index, the EEP change can be decomposed into energy and environmental technical efficiency change (catch-up effect) and energy and environmental technological change (frontier-shift effect). For the biennial periods " $t$ " and " $t+1$ ", we first select technology in the period " $t$ " as the benchmark and then examine the EEP change by the difference in DDFs from periods " $t$ " to " $t+1$ " referred to technology set $\mathbf{T}^{\mathrm{t}}$. Energy and environmental performance index (EEPI) used to measure the EEP change is defined as follows:

$$
E E P I^{t, t+1}\left(\mathbf{x}^{t}, \mathbf{e}^{t}, \mathbf{y}^{t}, \mathbf{b}^{t}, \mathbf{x}^{t+1}, \mathbf{e}^{t+1}, \mathbf{y}^{t+1}, \mathbf{b}^{t+1} ; \mathbf{g}\right)=\vec{D}^{t}\left(\mathbf{x}^{t}, \mathbf{e}^{t}, \mathbf{y}^{t}, \mathbf{b}^{t} ; \mathbf{g}\right)-\vec{D}^{t}\left(\mathbf{x}^{t+1}, \mathbf{e}^{t+1}, \mathbf{y}^{t+1}, \mathbf{b}^{t+1} ; \mathbf{g}\right)
$$

Similarly, EEPI can be defined with regard to the technology of the period " $t+1$ ":

$$
E E P I^{t, t+1}\left(\mathbf{x}^{t}, \mathbf{e}^{t}, \mathbf{y}^{t}, \mathbf{b}^{t}, \mathbf{x}^{t+1}, \mathbf{e}^{t+1}, \mathbf{y}^{t+1}, \mathbf{b}^{t+1} ; \mathbf{g}\right)=\vec{D}^{t+1}\left(\mathbf{x}^{t}, \mathbf{e}^{t}, \mathbf{y}^{t}, \mathbf{b}^{t}, \mathbf{g}\right)-\vec{D}^{t+1}\left(\mathbf{x}^{t+1}, \mathbf{e}^{t+1}, \mathbf{y}^{t+1}, \mathbf{b}^{t+1} ; \mathbf{g}\right)
$$

We compute the simple arithmetic mean of Equations (5) and (6) to eliminate the bias derived from arbitrary period selection:

$$
\begin{aligned}
& E E P I^{t, t+1}\left(\mathbf{x}^{t}, \mathbf{e}^{t}, \mathbf{y}^{t}, \mathbf{b}^{t}, \mathbf{x}^{t+1}, \mathbf{e}^{t+1}, \mathbf{y}^{t+1}, \mathbf{b}^{t+1} ; \mathbf{g}\right) \\
& =\frac{1}{2}\left\{\begin{array}{l}
{\left[\vec{D}^{t}\left(\mathbf{x}^{t}, \mathbf{e}^{t}, \mathbf{y}^{t}, \mathbf{b}^{t} ; \mathbf{g}\right)-\vec{D}^{t}\left(\mathbf{x}^{t+1}, \mathbf{e}^{t+1}, \mathbf{y}^{t+1}, \mathbf{b}^{t+1} ; \mathbf{g}\right)\right]} \\
\left.+\left[\vec{D}^{t+1}\left(\mathbf{x}^{t}, \mathbf{e}^{t}, \mathbf{y}^{t}, \mathbf{b}^{t}, \mathbf{g}\right)-\vec{D}^{t+1}\left(\mathbf{x}^{t+1}, \mathbf{e}^{t+1}, \mathbf{y}^{t+1}, \mathbf{b}^{t+1}, \mathbf{g}\right)\right]\right\}
\end{array}\right\}
\end{aligned}
$$

The energy and environmental technical efficiency is defined by the differences in DDFs from period " $t$ " to " $t+1$ " with respect to their own technologies; this reveals the change in distances of 
one observation in two periods " $t$ " and " $t+1$ " to the corresponding frontier of technologies " $t$ " and " $t+1$ " respectively.

$$
\text { effch }{ }^{t, t+1}\left[\mathbf{x}^{t}, \mathbf{e}^{t}, \mathbf{y}^{t}, \mathbf{b}^{t}, \mathbf{x}^{t+1}, \mathbf{e}^{t+1}, \mathbf{y}^{t+1}, \mathbf{b}^{t+1} ; \mathbf{g}\right]=\vec{D}^{t}\left(\mathbf{x}^{t}, \mathbf{e}^{t}, \mathbf{y}^{t}, \mathbf{b}^{t} ; \mathbf{g}\right)-\vec{D}^{t+1}\left(\mathbf{x}^{t+1}, \mathbf{e}^{t+1}, \mathbf{y}^{t+1}, \mathbf{b}^{t+1} ; \mathbf{g}\right)
$$

The energy and environmental technological change can be measured by comparing the distance from one observed data point in the period " $t$ " to the frontier of technology set of periods " $t$ " and " $t+1$ " respectively, which measures the distance between two technologies " $t$ " and " $t+1$ ".

$$
\text { techch }{ }^{t, t+1}\left(\mathbf{x}^{t}, \mathbf{e}^{t}, \mathbf{y}^{t}, \mathbf{b}^{t}, \mathbf{x}^{t+1}, \mathbf{e}^{t+1}, \mathbf{y}^{t+1}, \mathbf{b}^{t+1} ; \mathbf{g}\right)=\vec{D}^{t+1}\left(\mathbf{x}^{t}, \mathbf{e}^{t}, \mathbf{y}^{t}, \mathbf{b}^{t} ; \mathbf{g}\right)-\vec{D}^{t}\left(\mathbf{x}^{t}, \mathbf{e}^{t}, \mathbf{y}^{t}, \mathbf{b}^{t} ; \mathbf{g}\right)
$$

Similar to Equation (9), the energy and environmental technological change can be defined by comparing one observed data point in the period " $t+1$ " to the technology of period " $t$ " and “ $t+1$ "respectively:

$$
t e c h c h{ }^{t, t+1}\left(\mathbf{x}^{t}, \mathbf{e}^{t}, \mathbf{y}^{t}, \mathbf{b}^{t}, \mathbf{x}^{t+1}, \mathbf{e}^{t+1}, \mathbf{y}^{t+1}, \mathbf{b}^{t+1} ; \mathbf{g}\right)=\vec{D}^{t+1}\left(\mathbf{x}^{t+1}, \mathbf{e}^{t+1}, \mathbf{y}^{t+1}, \mathbf{b}^{t+1} ; \mathbf{g}\right)-\vec{D}^{t}\left(\mathbf{x}^{t+1}, \mathbf{e}^{t+1}, \mathbf{y}^{t+1}, \mathbf{b}^{t+1} ; \mathbf{g}\right)
$$

We also compute the simple arithmetic mean of Equations (9) and (10) to eliminate the bias of period selection:

$$
\begin{aligned}
& \text { techch }^{t, t+1}\left(\mathbf{x}^{t}, \mathbf{e}^{t}, \mathbf{y}^{t}, \mathbf{b}^{t}, \mathbf{x}^{t+1}, \mathbf{e}^{t+1}, \mathbf{y}^{t+1}, \mathbf{b}^{t+1} ; \mathbf{g}\right) \\
& =\frac{1}{2}\left\{\begin{array}{l}
{\left[\vec{D}^{t+1}\left(\mathbf{x}^{t}, \mathbf{e}^{t}, \mathbf{y}^{t}, \mathbf{b}^{t} ; \mathbf{g}\right)-\vec{D}^{t}\left(\mathbf{x}^{t}, \mathbf{e}^{t}, \mathbf{y}^{t}, \mathbf{b}^{t} ; \mathbf{g}\right)\right]} \\
+\left[\vec{D}^{t+1}\left(\mathbf{x}^{t+1}, \mathbf{e}^{t+1}, \mathbf{y}^{t+1}, \mathbf{b}^{t+1} ; \mathbf{g}\right)-\vec{D}^{t}\left(\mathbf{x}^{t+1}, \mathbf{e}^{t+1}, \mathbf{y}^{t+1}, \mathbf{b}^{t+1} ; \mathbf{g}\right)\right]
\end{array}\right\}
\end{aligned}
$$

Equations (7), (8) and (11) can be combined into a comprehensive equation which reflects the additive structure of the Luenberger productivity index:

$$
E E P I^{t, t+1}=e f f c h^{t, t+1}+t e c h c h^{t, t+1}
$$

Per the definition of $\vec{D}^{t}$ or $\vec{D}^{t+1}$, the biennial DDF based on $\mathbf{T}^{\mathbf{B}}$ instead of $\mathbf{T}$ is:

$$
\vec{D}^{\mathbf{B}}\left[\mathbf{x}, \mathbf{e}, \mathbf{y}, \mathbf{b} ; \mathbf{g}=\left(-\mathbf{g}_{\mathbf{x}},-\mathbf{g}_{\mathbf{e}}, \mathbf{g}_{\mathbf{y}},-\mathbf{g}_{\mathbf{b}}\right)\right]=\sup \left[\beta \mid\left(\mathbf{x}-\beta \mathbf{g}_{\mathbf{x}}, \mathbf{e}-\beta \mathbf{g}_{\mathbf{e}}, \mathbf{y}+\beta \mathbf{g}_{\mathbf{y}}, \mathbf{b}-\beta \mathbf{g}_{\mathbf{b}}\right) \in \mathbf{T}^{\mathbf{B}}\right]
$$

Similar to the definition of above Luenberger productivity index, the biennial Luenberger productivity index has two components:

$$
\begin{gathered}
E E P I_{B}^{t, t+1}\left(\mathbf{x}^{t}, \mathbf{e}^{t}, \mathbf{y}^{t}, \mathbf{b}^{t}, \mathbf{x}^{t+1}, \mathbf{e}^{t+1}, \mathbf{y}^{t+1}, \mathbf{b}^{t+1} ; \mathbf{g}\right)=\vec{D}^{B}\left(\mathbf{x}^{t}, \mathbf{e}^{t}, \mathbf{y}^{t}, \mathbf{b}^{t} ; \mathbf{g}\right)-\vec{D}^{B}\left(\mathbf{x}^{t+1}, \mathbf{e}^{t+1}, \mathbf{y}^{t+1}, \mathbf{b}^{t+1} ; \mathbf{g}\right) \\
\operatorname{effchch}_{B}^{t, t+1}\left(\mathbf{x}^{t}, \mathbf{e}^{t}, \mathbf{y}^{t}, \mathbf{b}^{t}, \mathbf{x}^{t+1}, \mathbf{e}^{t+1}, \mathbf{y}^{t+1}, \mathbf{b}^{t+1} ; \mathbf{g}\right)=\vec{D}^{t}\left(\mathbf{x}^{t}, \mathbf{e}^{t}, \mathbf{y}^{t}, \mathbf{b}^{t} ; \mathbf{g}\right)-\vec{D}^{t+1}\left(\mathbf{x}^{t+1}, \mathbf{e}^{t+1}, \mathbf{y}^{t+1}, \mathbf{b}^{t+1} ; \mathbf{g}\right) \\
\operatorname{techch}_{B}^{t, t+1}\left(\mathbf{x}^{t}, \mathbf{e}^{t}, \mathbf{y}^{t}, \mathbf{b}^{t}, \mathbf{x}^{t+1}, \mathbf{e}^{t+1}, \mathbf{y}^{t+1}, \mathbf{b}^{t+1} ; \mathbf{g}\right)= \\
=\left[\vec{D}^{B}\left(\mathbf{x}^{t}, \mathbf{e}^{t}, \mathbf{y}^{t}, \mathbf{b}^{t} ; \mathbf{g}\right)-\vec{D}^{t}\left(\mathbf{x}^{t}, \mathbf{e}^{t}, \mathbf{y}^{t}, \mathbf{b}^{t} ; \mathbf{g}\right)\right] \\
-\left[\vec{D}^{B}\left(\mathbf{x}^{t+1}, \mathbf{e}^{t+1}, \mathbf{y}^{t+1}, \mathbf{b}^{t+1} ; \mathbf{g}\right)-\vec{D}^{t+1}\left(\mathbf{x}^{t+1}, \mathbf{e}^{t+1}, \mathbf{y}^{t+1}, \mathbf{b}^{t+1} ; \mathbf{g}\right)\right] \\
E E P I_{B}^{t, t+1}=e f f c h_{B}^{t, t+1}+t e c h c h_{B}^{t, t+1}
\end{gathered}
$$




\subsection{Energy and Environmental Performance Measurement with Non-Radial DEA Model}

Based on the definitions of DDFs (Equations (4) and (13)) and estimated technology sets of $\hat{\mathbf{T}}$ and $\hat{\mathbf{T}}^{\mathbf{B}}$ (Models (2) and (3)), the radial DDFs can be estimated by the following DEA models:

$$
\begin{aligned}
& \hat{\vec{D}}^{t}[\mathbf{x}, \mathbf{e}, \mathbf{y}, \mathbf{b} ; \mathbf{g}=(-\mathbf{x},-\mathbf{e}, \mathbf{y},-\mathbf{b})]=\max \beta \\
& \sum_{k=1}^{K} \lambda_{k}^{t} x_{m k}^{t} \leq(1-\beta) x_{m o} \quad m=1,2, \cdots, M \\
& \sum_{k=1}^{K} \lambda_{k}^{t} e_{q k}^{t} \leq(1-\beta) e_{q o} q=1,2, \cdots, Q \\
& \sum_{k=1}^{K} \lambda_{k}^{t} y_{n k}^{t} \geq(1+\beta) y_{n o} n=1,2, \cdots, N \\
& \sum_{k=1}^{K} \lambda_{k}^{t} b_{j k}^{t}=(1-\beta) b_{j o} j=1,2, \cdots, J \\
& \lambda_{k}^{t} \geq 0 ; \quad k=1,2, \cdots, K \\
& \hat{\rightarrow}^{\mathbf{B}} \\
& \hat{\vec{D}}^{\mathbf{B}}[\mathbf{x}, \mathbf{e}, \mathbf{y}, \mathbf{b} ; \mathbf{g}=(-\mathbf{x},-\mathbf{e}, \mathbf{y},-\mathbf{b})]=\max \beta \\
& \sum_{k=1}^{K} \lambda_{k}^{t+1} x_{m k}^{t+1}+\sum_{k=1}^{K} \lambda_{k}^{t} x_{m k}^{t} \leq(1-\beta) x_{m o} m=1,2, \cdots, M \\
& \sum_{k=1}^{K} \lambda_{k}^{t+1} e_{q k}^{t+1}+\sum_{k=1}^{K} \lambda_{k}^{t} e_{q k}^{t} \leq(1-\beta) e_{q o} q=1,2, \cdots, Q \\
& \sum_{k=1}^{K} \lambda_{k}^{t+1} y_{n k}^{t+1}+\sum_{k=1}^{K} \lambda_{k}^{t} y_{n k}^{t} \geq(1+\beta) y_{n o} n=1,2, \cdots, N \\
& \sum_{k=1}^{K} \lambda_{k}^{t+1} b_{j k}^{t+1}+\sum_{k=1}^{K} \lambda_{k}^{t} b_{j k}^{t}=(1-\beta) b_{j o} j=1,2, \cdots, J \\
& \lambda_{k}^{t} \geq 0 ; \lambda_{k}^{t+1} \geq 0 ; k=1,2, \cdots, K
\end{aligned}
$$

Traditional and biennial DDFs can be computed by Models (18) and (19), respectively. $\beta$ denotes the slack ratio (adjustment rate) or "inefficiency score". If $\beta=0$, then the corresponding DMU is considered to be efficient and with no improvement potential. $\beta>0$ indicates that the corresponding DMU is inefficient and has not yet achieved the relative optimization. Models (18) and (19) are regarded as radial DDFs with the same adjustment rate.

The radial DDF gives the same contraction (expansion) to all the inputs (outputs) and thus may have weak technical efficiency. Increasing desirable outputs and decreasing inputs and undesirable outputs can be further achieved under the current technical conditions, i.e., the radial DDF overestimates the efficiency. The non-radial DDF can further identify potential in increasing inputs and decreasing outputs, so we use a non-radial DDF model to measure EEP here. Mathematically, traditional and biennial radial DDFs can be improved by the following DEA models:

$$
\begin{aligned}
& \hat{\vec{D}}^{t}[\mathbf{x}, \mathbf{e}, \mathbf{y}, \mathbf{b} ; \mathbf{g}=(-\mathbf{x},-\mathbf{e}, \mathbf{y},-\mathbf{b})] \\
& =\max \frac{1}{4}\left(\frac{1}{M} \sum_{m=1}^{M} \beta_{m}+\frac{1}{Q} \sum_{q=1}^{Q} \beta_{q}+\frac{1}{N} \sum_{n=1}^{N} \beta_{n}+\frac{1}{J} \sum_{j=1}^{J} \beta_{j}\right) \\
& \sum_{k=1}^{K} \lambda_{k}^{t} x_{m k}^{t} \leq\left(1-\beta_{m}\right) x_{m o} \quad m=1,2, \cdots, M \\
& \sum_{k=1}^{K} \lambda_{k}^{t} e_{q k}^{t} \leq\left(1-\beta_{q}\right) e_{q o} \quad q=1,2, \cdots, Q \\
& \sum_{k=1}^{K} \lambda_{k}^{t} y_{n k}^{t} \geq\left(1+\beta_{n}\right) y_{n o} \quad n=1,2, \cdots, N \\
& \sum_{k=1}^{K} \lambda_{k}^{t} b_{j k}^{t}=\left(1-\beta_{j}\right) b_{j o} j=1,2, \cdots, J \\
& \lambda_{k}^{t} \geq 0 ; \quad k=1,2, \cdots, K
\end{aligned}
$$




$$
\begin{aligned}
& \hat{\vec{D}}^{\mathbf{B}}[\mathbf{x}, \mathbf{e}, \mathbf{y}, \mathbf{b} ; \mathbf{g}=(-\mathbf{x},-\mathbf{e}, \mathbf{y},-\mathbf{b})] \\
& =\max \frac{1}{4}\left(\frac{1}{M} \sum_{m=1}^{M} \beta_{m}+\frac{1}{Q} \sum_{q=1}^{Q} \beta_{q}+\frac{1}{N} \sum_{n=1}^{N} \beta_{n}+\frac{1}{J} \sum_{j=1}^{J} \beta_{j}\right) \\
& \sum_{k=1}^{K} \lambda_{k}^{t+1} x_{m k}^{t+1}+\sum_{k=1}^{K} \lambda_{k}^{t} x_{m k}^{t} \leq\left(1-\beta_{m}\right) x_{m o} m=1,2, \cdots, M \\
& \sum_{k=1}^{K} \lambda_{k}^{t+1} e_{q k}^{t+1}+\sum_{k=1}^{K} \lambda_{k}^{t} e_{q k}^{t} \leq\left(1-\beta_{q}\right) e_{q o} q=1,2, \cdots, Q \\
& \sum_{k=1}^{K} \lambda_{k}^{t+1} y_{n k}^{t+1}+\sum_{k=1}^{K} \lambda_{k}^{t} y_{n k}^{t} \geq\left(1+\beta_{n}\right) y_{n o} n=1,2, \cdots, N \\
& \sum_{k=1}^{K} \lambda_{k}^{t+1} b_{j k}^{t+1}+\sum_{k=1}^{K} \lambda_{k}^{t} b_{j k}^{t}=\left(1-\beta_{j}\right) b_{j o} j=1,2, \cdots, J \\
& \lambda_{k}^{t} \geq 0 ; \lambda_{k}^{t+1} \geq 0 ; k=1,2, \cdots, K
\end{aligned}
$$

In Models (20) and (21), $\beta_{m}, \beta_{q}, \beta_{n}$, or $\beta_{j}$ represents the ratio of the slack to a non-energy input, energy input, desirable output, or undesirable output respectively. If $\beta_{m}=\beta_{q}=\beta_{n}=\beta_{j}$, Models (20) and (21) are converted into Models (18) and (19). The non-radial DDF allows us to exploit slacks more exhaustively with stronger discrimination power than the radial DDF [55]. We mainly focused on energy conservation and pollution reduction in this study, so the directional vector is set to $\mathbf{g}=(0,-\mathbf{e}, 0,-\mathbf{b})$ here. The DDF we used can be calculated by the following DEA linear programming models:

$$
\begin{aligned}
& \overrightarrow{\vec{D}}^{t}[\mathbf{x}, \mathbf{e}, \mathbf{y}, \mathbf{b} ; \mathbf{g}=(\mathbf{0},-\mathbf{e}, \mathbf{0},-\mathbf{b})] \\
& =\max \frac{1}{2}\left(\frac{1}{Q} \sum_{q=1}^{Q} \beta_{q}+\frac{1}{J} \sum_{j=1}^{J} \beta_{j}\right) \\
& \sum_{k=1}^{K} \lambda_{k}^{t} x_{m k}^{t} \leq x_{m o} \quad m=1,2, \cdots, M \\
& \sum_{k=1}^{K} \lambda_{k}^{t} e_{q k}^{t} \leq\left(1-\beta_{q}\right) e_{q o} \quad q=1,2, \cdots, Q \\
& \sum_{k=1}^{K} \lambda_{k}^{t} y_{n k}^{t} \geq y_{n o} \quad n=1,2, \cdots, N \\
& \sum_{k=1}^{K} \lambda_{k}^{t} b_{j k}^{t}=\left(1-\beta_{j}\right) b_{j o} \quad j=1,2, \cdots, J \\
& \lambda_{k}^{t} \geq 0 ; \quad k=1,2, \cdots, K \\
& \hat{\vec{D}}^{\mathbf{B}}[\mathbf{x}, \mathbf{e}, \mathbf{y}, \mathbf{b} ; \mathbf{g}=(\mathbf{0},-\mathbf{e}, \mathbf{0},-\mathbf{b})] \\
& =\max \frac{1}{2}\left(\frac{1}{Q} \sum_{q=1}^{Q} \beta_{q}+\frac{1}{J} \sum_{j=1}^{J} \beta_{j}\right) \\
& \sum_{k=1}^{K} \lambda_{k}^{t+1} x_{m k}^{t+1}+\sum_{k=1}^{K} \lambda_{k}^{t} x_{m k}^{t} \leq x_{m o} \quad m=1,2, \cdots, M \\
& \sum_{k=1}^{K} \lambda_{k}^{t+1} e_{q k}^{t+1}+\sum_{k=1}^{K} \lambda_{k}^{t} e_{q k}^{t} \leq\left(1-\beta_{q}\right) e_{q o} \quad q=1,2, \cdots, Q \\
& \sum_{k=1}^{K} \lambda_{k}^{t+1} y_{n k}^{t+1}+\sum_{k=1}^{K} \lambda_{k}^{t} y_{n k}^{t} \geq y_{n o} \quad n=1,2, \cdots, N \\
& \sum_{k=1}^{K} \lambda_{k}^{t+1} b_{j k}^{t+1}+\sum_{k=1}^{K} \lambda_{k}^{t} b_{j k}^{t}=\left(1-\beta_{j}\right) b_{j o} \quad j=1,2, \cdots, J \\
& \lambda_{k}^{t} \geq 0 ; \quad \lambda_{k}^{t+1} \geq 0 ; \quad k=1,2, \cdots, K
\end{aligned}
$$

In Models (22) and (23), $\beta_{q}$ and $\beta_{j}$ represent the ratios of energy conservation and emission abatement, respectively. In Model (22), $1-\beta_{q}$ represents the specific energy performance while $1-\beta_{j}$ represents the specific undesirable output performance (wastewater, $\mathrm{SO}_{2}$ or soot performance). $\vec{D}^{t}\left(\mathbf{x}^{t}, \mathbf{e}^{t}, \mathbf{y}^{t}, \mathbf{b}^{t} ; \mathbf{g}\right)$ represents the energy and environmental inefficiency, so we can calculate EEP by $1-\vec{D}^{t}\left(\mathbf{x}^{t}, \mathbf{e}^{t}, \mathbf{y}^{t}, \mathbf{b}^{t} ; \mathbf{g}\right)$. 
If input-output combination $(\mathbf{x}, \mathbf{e}, \mathbf{y}, \mathbf{b})$ is observed in the period " $t$ " for two technologies in the period " $t$ " and " $t+1$ " respectively, we can estimate $\vec{D}^{t}\left(\mathbf{x}^{t}, \mathbf{e}^{t}, \mathbf{y}^{t}, \mathbf{b}^{t} ; \mathbf{g}\right)$ and $\vec{D}^{t+1}\left(\mathbf{x}^{t}, \mathbf{e}^{t}, \mathbf{y}^{t}, \mathbf{b}^{t} ; \mathbf{g}\right)$ with Model (22). We can estimate $\vec{D}^{t}\left(\mathbf{x}^{t+1}, \mathbf{e}^{t+1}, \mathbf{y}^{t+1}, \mathbf{b}^{t+1} ; \mathbf{g}\right)$ and $\vec{D}^{t+1}\left(\mathbf{x}^{t+1}, \mathbf{e}^{t+1}, \mathbf{y}^{t+1}, \mathbf{b}^{t+1} ; \mathbf{g}\right)$ similarly. We can also estimate $\vec{D}^{B}\left(\mathbf{x}^{t}, \mathbf{e}^{t}, \mathbf{y}^{t}, \mathbf{b}^{t} ; \mathbf{g}\right)$ and $\vec{D}^{B}\left(\mathbf{x}^{t+1}, \mathbf{e}^{t+1}, \mathbf{y}^{t+1}, \mathbf{b}^{t+1} ; \mathbf{g}\right)$ by employing Model (23) with production activity $(\mathbf{x}, \mathbf{e}, \mathbf{y}, \mathbf{b})$ observed in the period " $t$ " and " $t+1$ " respectively.

To calculate the Luenberger EEPI which represents the EEP change, we need to calculate six DDFs (activities in " $t$ " and " $t+1$ " refer to technologies in the period " $t$ ", " $t+1$ " and pooled respectively) by Models (22) and (23). Given that different undesirable output structures impact the EEP, a non-radial efficiency measure can help us identify specific effects and contributions of energy factor and specific undesirable outputs. The total EEPI can be further decomposed into specific EEPIs to analyze the contributions of specific undesirable outputs and energy inputs on total EEPI.

\subsection{Exploratory Spatial Data Analysis-Moran's Index}

The sample data we used contains abundant spatial information, so we sought to consider the spatial effects on EEP among different cities. We did so by applying Exploratory Spatial Data Analysis (ESDA) to describe the spatial distribution of the EEP. We used Moran's I statistic to measure the spatial correlation at the city level, including global spatial correlation and local spatial correlation [56].

(1) Global Moran's I statistics

The global Moran's I statistics reflect the similarity of attributes with their neighborhoods:

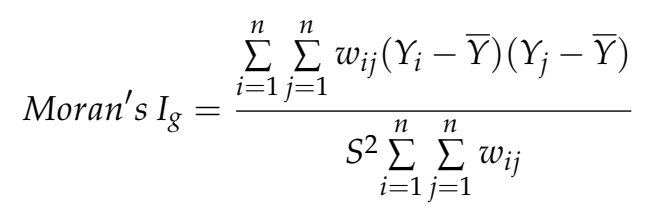

where $Y_{i}$ represents the observed value in the ith city; $n$ represents the number of the cities; $w_{i j}$ represents the spatial weight matrix which reflects the spatial adjacent relationship in the $i$ th and $j$ th cities. Global Moran's I ranges from -1 to 1: value less than 0 represents a negative correlation, 0 represents an uncorrelated relationship, and greater than 0 represents a positive correlation. As the global Moran's I moves towards -1 , the spatial differences among cities become more obvious. If the obtained value of global Moran's $I$ is near to 1, there are more intimate relations (e.g., high-value clusters or low-value clusters) among cities.

(2) Local Moran's I statistics

$$
I_{i}=\frac{\left(x_{i}-\bar{x}\right)}{S^{2}} \sum_{j} w_{i j}\left(x_{j}-\bar{x}\right)
$$

If $I_{i}$ is greater than 0 , the $i$ th spatial unit is similar to its neighbors (i.e., "high-high" or "low-low"); $I_{i}$, with a value lower than 0 represents dissimilarities to neighbors ("high-low" or "low-high"). We can also visually identify the high-value clusters and low-value clusters according to the map of local indicators of spatial association (LISA).

\subsection{Geographically Weighted Regression Model}

The spatial heterogeneity of our data means that explanatory variables have varying extent of influence on the explained variable in different areas. Under the traditional econometric regression model, regression parameters are same across whole regions and regional differences are neglected. The geographically weighted regression (GWR) model [57,58], which takes the regional difference into account, allows regression parameters to change along with the geographical position. Regression 
parameters in GWR are a data set rather than a fixed coefficient. The GWR model can be derived as follows:

$$
y_{i}=\beta_{0}\left(u_{i}, v_{i}\right)+\sum_{k=1}^{K} \beta_{k}\left(u_{i}, v_{i}\right) x_{i k}+\varepsilon_{i}
$$

where the vector $\mathbf{y}$ represents the explained variable; the vector $\mathbf{x}$ represents explanatory variables; $\left(u_{i}, v_{i}\right)$ is the space coordinate (longitude and latitude) in the area $i . \beta_{k}\left(u_{i}, v_{i}\right)$ is the regression parameter for the $k$ th explanatory variable in the area $i$. $\varepsilon_{i}$ is random error; we assume that $\varepsilon_{i} \sim$ $N\left(0, \sigma^{2}\right)$ and $\operatorname{cov}\left(\varepsilon_{i}, \varepsilon_{j}\right)=0(i \neq j)$. To estimate regression parameters, we assign $w_{1}\left(u_{i}, v_{i}\right), w_{2}\left(u_{i}, v_{i}\right)$, $\cdots, w_{n}\left(u_{i}, v_{i}\right)$ for the area $i$ to represent influences from all other areas [59]. According to the weighted least square method, we can then estimate the regression equation in $\left(u_{i}, v_{i}\right)$ by minimizing the following equation:

$$
\sum_{i=1}^{n} w_{i}\left(u_{i}, v_{i}\right)\left[y_{i}-\beta_{0}\left(u_{i}, v_{i}\right)-\beta_{1}\left(u_{i}, v_{i}\right) \mathrm{x}_{i 1}-\cdots-\beta_{K}\left(u_{i}, v_{i}\right) x_{i k}\right]^{2}
$$

with

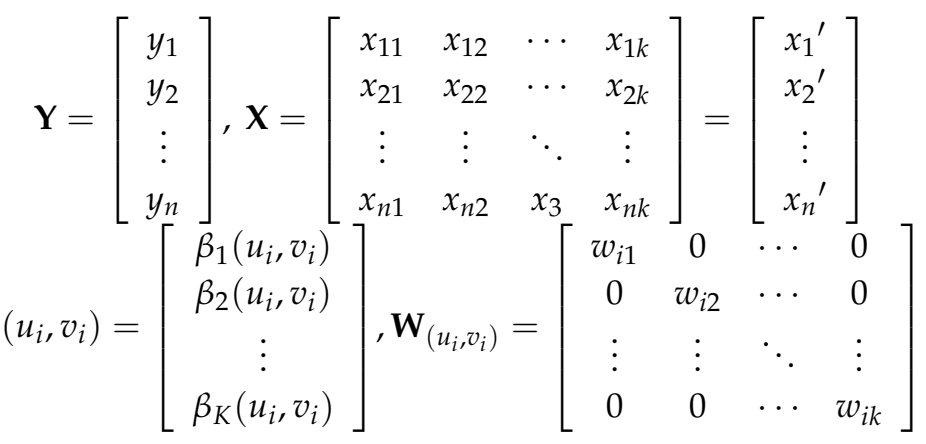

We can then derive $\hat{\beta}\left(u_{i}, v_{i}\right)=\left(\mathbf{X}^{T} \mathbf{W}_{\left(u_{i}, v_{i}\right)} \mathbf{X}\right)^{-1} \mathbf{X}^{T} \mathbf{W}_{\left(u_{i}, v_{i}\right)} \mathbf{Y}$. The spatial weighting function is the key to the above GWR model. Here, we use a Gaussian weighting function as the spatial weighting function [59].

\section{Empirical Study}

\subsection{Data Source and Description}

We initiated our analysis using a data set containing 283 cities in China over 2010-2014. Certain official statistics measurement criteria changed significantly in 2010, so we set the time period from 2010 to 2014 to maintain comparability across the data. We chose labor and capital as the two non-energy inputs. Labor is defined by the number of employees in a city's industrial sectors (i.e., the secondary industry except for construction). To define capital, we referred to the total fixed assets and current assets at constant prices in 2010 [46]. We used the price indexes from corresponding provinces because fixed asset investment price indexes are not available at the city level. With regard to current assets, we adopted the consumer price index from the corresponding city to eliminate the influence of fluctuations in prices. We could not obtain total energy consumption in the industrial sectors at the city level, so we chose the electricity consumption as an approximate substitution [48]. We used gross industrial output as the sole desirable output and adopted the ex-factory price index of industrial products to eliminate price fluctuations. The "undesirable outputs" referred to in this paper contain three specific pollutants: industrial wastewater, industrial sulfur dioxide $\left(\mathrm{SO}_{2}\right)$, and industrial soot. We also used the ratio of value added of the service industry in the city's GDP to analyze GWR. Data was collected from the China City Statistical Yearbook (2011-2015) [60] and China Provincial Statistical Yearbook (2011-2015) [61]. The descriptive statistics of inputs and outputs we applied to empirical analysis are shown in Table 1. 
Table 1. Descriptive statistics of inputs and outputs in 2010-2014.

\begin{tabular}{cccccccc}
\hline Index & Variable & Unit & Quantity & Mean & St.Dev & Min & Max \\
\hline \multirow{3}{*}{ Non-energy input } & Labor force & 10 thousand persons & $283 \times 5$ & 19.16 & 28.18 & 0.39 & 260.92 \\
& Current assets & billion Yuan & $283 \times 5$ & 116.27 & 196.44 & 0.83 & 1808.43 \\
& Fixed assets & billion Yuan & $283 \times 5$ & 90.15 & 106.34 & 0.86 & 827.94 \\
\hline \multirow{2}{*}{ Energy input } & Industrial electricity & 100 million kWh & $283 \times 5$ & 60.19 & 91.97 & 0.045 & 805.76 \\
\hline Desirable output & Gross industrial output & billion Yuan & $283 \times 5$ & 310.31 & 423.71 & 1.53 & 3278.23 \\
\hline \multirow{2}{*}{ Undesirable output } & Industrial wastewater & million tons & $283 \times 5$ & 74.71 & 84.99 & 0.23 & 868.04 \\
& Industrial sulfur & thousand tons & $283 \times 5$ & 58.78 & 57.33 & 0.002 & 572.75 \\
& dioxide & thousand tons & $283 \times 5$ & 41.71 & 188.64 & 0.034 & 5168.81 \\
\hline
\end{tabular}

\subsection{Results and Discussion}

\subsubsection{Static Energy and Environmental Performance}

Descriptive Statistics of Energy and Environmental Performance

We first compared the EEP (calculated by $\left(1-\vec{D}^{t}\left(\mathbf{x}^{t}, \mathbf{e}^{t}, \mathbf{y}^{t}, \mathbf{b}^{t} ; \mathbf{g}\right)\right)$ with Model (22)) and its decompositions consisting of energy, wastewater, $\mathrm{SO}_{2}$ and soot emission performances (measured by $\left(1-\beta_{q}\right)$ and $\left(1-\beta_{j}\right)$ with Model (22)) at both national and regional levels. Our calculations of the mean, standard deviation, minimum value, and maximal value in the four areas involve five-year $x$ cities' total performance and its decompositions (where $x$ represents the number of cities in the corresponding area) encompassing both temporal and spatial dimensions. Table 2 shows the descriptive statistics of total EEP and sub-EEPs for 283 cities in China across 2010-2014. Beside the overall descriptive statistics at national level, we detailed and sorted them at regional level (i.e., eastern, central, western and northeastern areas) for further comparisons. All the EEPs in the eastern area are higher than national level; meanwhile, the northeastern and western areas obtain lower values in EEPs compared to national level.

Table 2. Descriptive statistics of energy and environmental performance (EEP) and sub-performances.

\begin{tabular}{ccccccc}
\hline Performance (Efficiency) & Area & Quantity & Mean & St.Dev & Min & Max \\
\hline \multirow{4}{*}{ Total } & East & $87 \times 5$ & 0.473 & 0.298 & 0.069 & 1.000 \\
& China & $283 \times 5$ & 0.365 & 0.292 & 0.016 & 1.000 \\
& Central & $99 \times 5$ & 0.362 & 0.282 & 0.031 & 1.000 \\
& Northeast & $33 \times 5$ & 0.272 & 0.236 & 0.025 & 1.000 \\
& West & $64 \times 5$ & 0.270 & 0.276 & 0.016 & 1.000 \\
\hline \multirow{5}{*}{ Energy } & East & $87 \times 5$ & 0.456 & 0.328 & 0.042 & 1.000 \\
& Central & $99 \times 5$ & 0.364 & 0.304 & 0.012 & 1.000 \\
& China & $283 \times 5$ & 0.358 & 0.315 & 0.008 & 1.000 \\
& West & $64 \times 5$ & 0.259 & 0.291 & 0.008 & 1.000 \\
& Northeast & $33 \times 5$ & 0.257 & 0.253 & 0.019 & 1.000 \\
\hline \multirow{5}{*}{ Wastewater } & East & $87 \times 5$ & 0.418 & 0.326 & 0.015 & 1.000 \\
& China & $283 \times 5$ & 0.355 & 0.308 & 0.011 & 1.000 \\
& Central & $99 \times 5$ & 0.347 & 0.303 & 0.038 & 1.000 \\
& Northeast & $33 \times 5$ & 0.333 & 0.283 & 0.024 & 1.000 \\
& West & $64 \times 5$ & 0.280 & 0.292 & 0.011 & 1.000 \\
\hline \multirow{6}{*}{} & East & $87 \times 5$ & 0.481 & 0.330 & 0.037 & 1.000 \\
& China & $283 \times 5$ & 0.358 & 0.321 & 0.007 & 1.000 \\
& Central & $99 \times 5$ & 0.338 & 0.314 & 0.020 & 1.000 \\
& Northeast & $33 \times 5$ & 0.281 & 0.266 & 0.017 & 1.000 \\
& West & $64 \times 5$ & 0.264 & 0.303 & 0.007 & 1.000 \\
\hline
\end{tabular}


Table 2. Cont.

\begin{tabular}{ccccccc}
\hline Performance (Efficiency) & Area & Quantity & Mean & St.Dev & Min & Max \\
\hline \multirow{6}{*}{ Soot } & East & $87 \times 5$ & 0.572 & 0.336 & 0.014 & 1.000 \\
& China & $283 \times 5$ & 0.403 & 0.339 & 0.014 & 1.000 \\
& Central & $99 \times 5$ & 0.356 & 0.311 & 0.001 & 1.000 \\
& West & $64 \times 5$ & 0.299 & 0.311 & 0.004 & 1.000 \\
& Northeast & $33 \times 5$ & 0.246 & 0.267 & 0.014 & 1.000 \\
\hline
\end{tabular}

Distribution Dynamic Analysis of Energy and Environmental Performance

We next tracked the EEP evolution for 283 cities in China via the distribution dynamics approach [62-64]. Each city's EEP and its decompositions were divided by 283 cities' yearly average levels to form the corresponding relative performance indicators. These indicators can then be used to estimate the kernel densities and stochastic kernels.

Figure 1 shows the distributions of kernel densities for the total performance and sub-performances. The distribution of total performance in 2010 is bimodal with more than $80 \%$ of cities' performance distributed around 0.5 times the average performance level and other cities' performance concentrated on 2.5 times level (possessed by the best performers). Most cities' total performances were below average in 2010, but a select few cities performed extremely well and formed a small convergence club led by best performers. In 2014, the distribution of total performance nearly reached around 0.5 times the average performance level; the small convergence club dispersed and members in it became smaller. The ergodic distribution indicates clear convergence to 0.5 times the average level and small convergence club would nearly disappear. Other kernel density plots for sub-performances indicate that: (1) energy performance features strong convergence to 0.5 times the average performance level; (2) small convergence clubs for environmental performances are more obvious than energy performance.

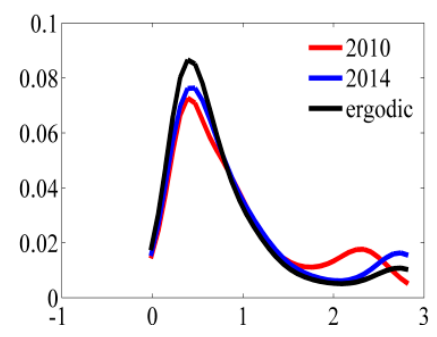

(a)

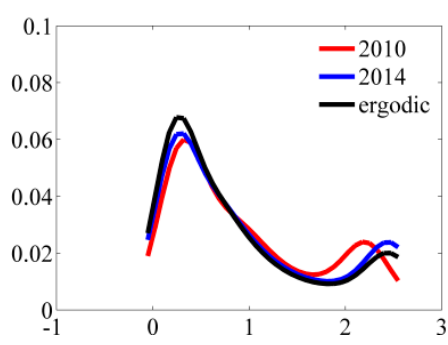

(d)

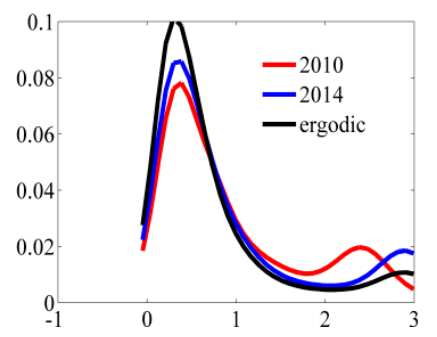

(b)

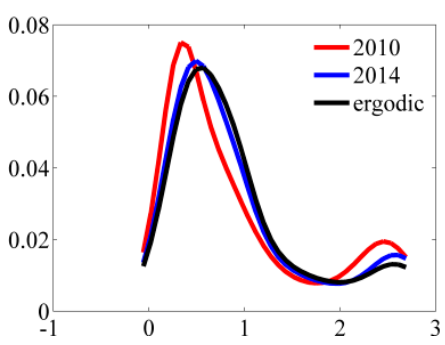

(e)

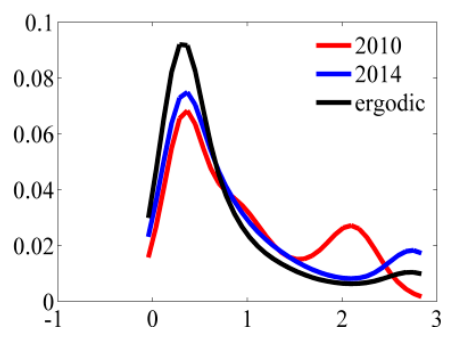

(c)

Figure 1. Distributions of total performance and sub-performances. (a) Total; (b) Energy; (c) $\mathrm{SO}_{2}$; (d) Soot; (e) Wastewater.

As shown in the 3D stochastic kernel and 2D contour part plots (Figures 2 and 3), for cities with below-average levels in total performance and sub-performances, the transition probability generally moves counter-clockwise from the $45^{\circ}$ diagonal—cities with relatively low EEP compared to the 
average level remarkably improved over the study period. Cities with above-average performance, conversely, can be divided into two groups: The first group, the small convergence club led by the best performers, remain near the $45^{\circ}$ diagonal in the upper right-hand corner. In the second group, cities with high total performance and sub-performances gradually decrease in efficiency and converge to average levels.

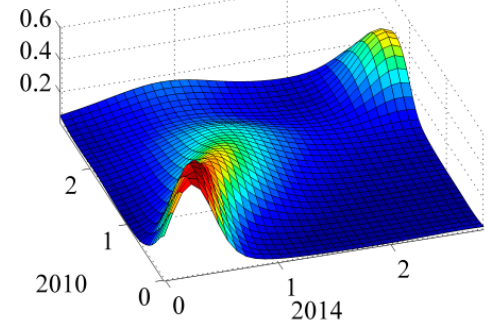

(a)

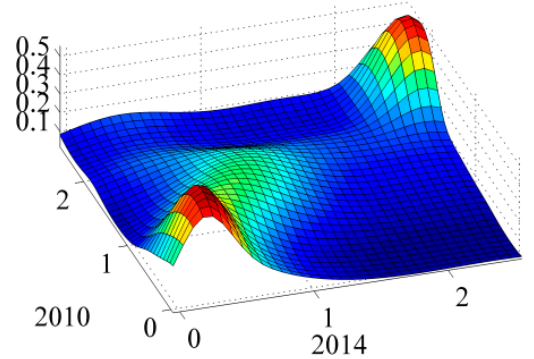

(d)

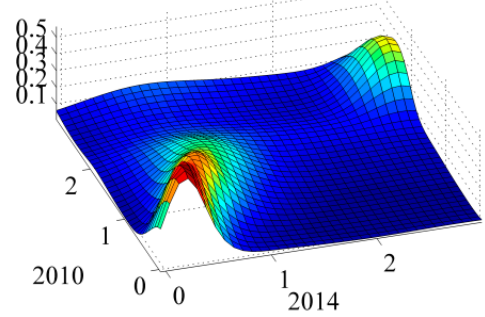

(b)

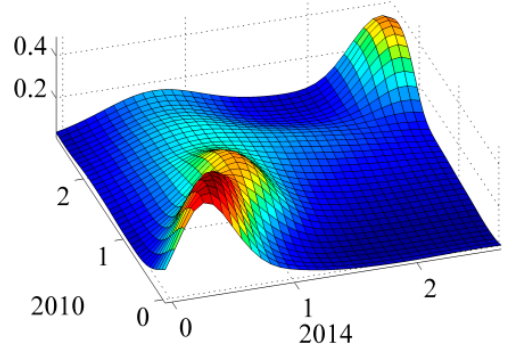

(e)

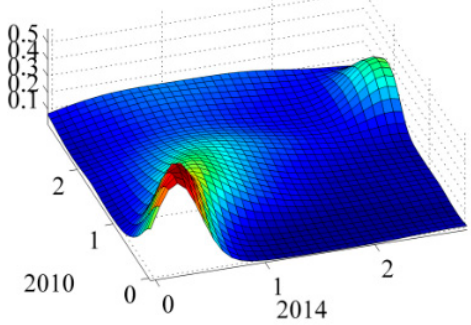

(c)

Figure 2. A 3D surface of stochastic kernel plots for total and sub-performances. (a) Total; (b) Energy; (c) $\mathrm{SO}_{2} ;$ (d) Soot; (e) Wastewater.

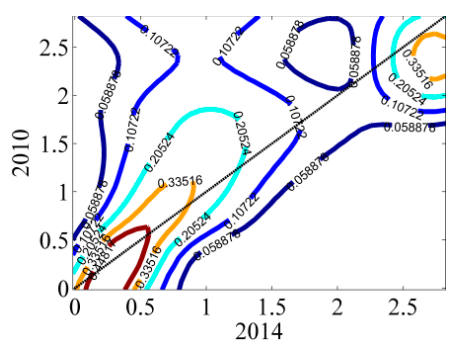

(a)

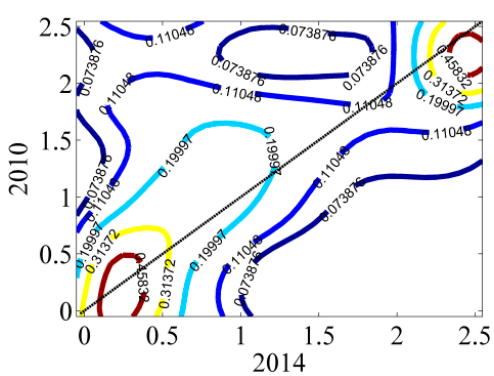

(d)

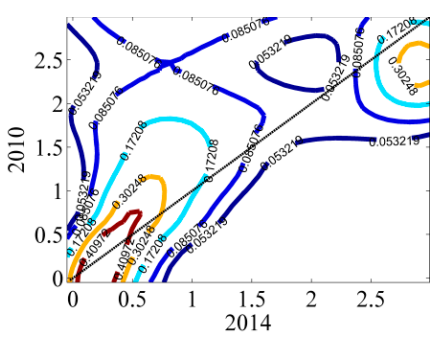

(b)

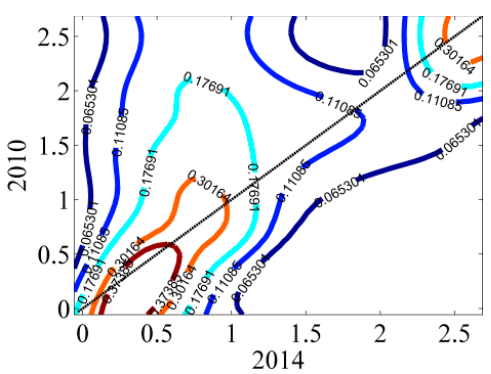

(e)

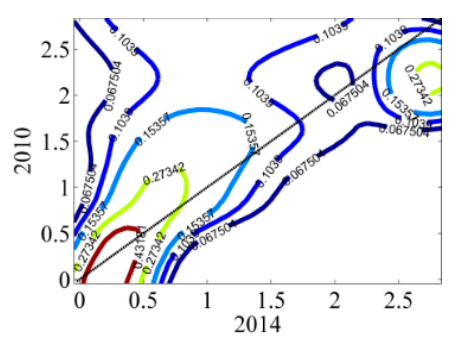

(c)

Figure 3. Contour stochastic kernel plots for total and sub-performances. (a) Total; (b) Energy; (c) $\mathrm{SO}_{2}$; (d) Soot; (e) Wastewater. 
Analysis of Best and Worst Performers

Identifying the best performers can provide good benchmarks for cities with lower efficiency in terms of energy conservation and emissions abatement. If EEP equals $1\left(D^{\mathrm{t}}\left(\mathbf{x}^{\mathrm{t}}, \mathbf{e}^{\mathrm{t}}, \mathbf{y}^{\mathrm{t}}, \mathbf{b}^{\mathrm{t}} ; \mathbf{g}\right)=0\right)$, i.e., the city was located in the production frontier for at least in one year between 2010 and 2014, the city is defined as a "best performer". As shown in Figure 4, the best performers are mainly located in Guangdong, Shandong, Jiangsu, Jiangxi, Sichuan, and Hainan provinces. The best performers possess advanced service industries, which generally consume few resources, or have high ecological quality. In Qingdao, Shenzhen, and Dongguan, for example, the ratio of service industry to GDP was $51.22 \%, 57.39 \%$, and $52.14 \%$ in 2014 , respectively. The service industry consumes relatively little energy though it does require a great deal of labor, capital, and technology. Besides, these developed cities with sufficient funding also can improve their energy conservation and abatement ability via technical innovation and advanced managerial experience. These cities consume less energy and emit less pollution while maximizing desirable outputs. Provinces such as Jiangxi, Sichuan, and Hainan have less developed economies but still exhibit high EEP due to natural endowments (high ecological quality) and economic support from tourism.

A city with EEP no more than $0.1\left(D^{\mathrm{t}}\left(\mathbf{x}^{\mathrm{t}}, \mathbf{e}^{\mathrm{t}}, \mathbf{y}^{\mathrm{t}}, \mathbf{b}^{\mathrm{t}} ; \mathbf{g}\right)>0.9\right)$ in all years of 2010-2014 is defined as a "worst performer". As shown in Figure 4, the worst performers are mainly distributed in Heilongjiang, Guangxi, Ningxia, and Shanxi provinces which are generally rich in coal or nonferrous metal resources. Cities like Datong (Shanxi), Shizuishan (Ningxia), Huainan (Anhui) and Hegang (Heilongjiang) are important coal bases of China. A great deal of pollutants are emitted by coal exploitation and processing. Other cities like Guigang (Guangxi) and Baise (also Guangxi) are important nonferrous metal bases of China. Nonferrous metallurgy likewise produces substantial air pollutants as well as mercury and chromium pollution.

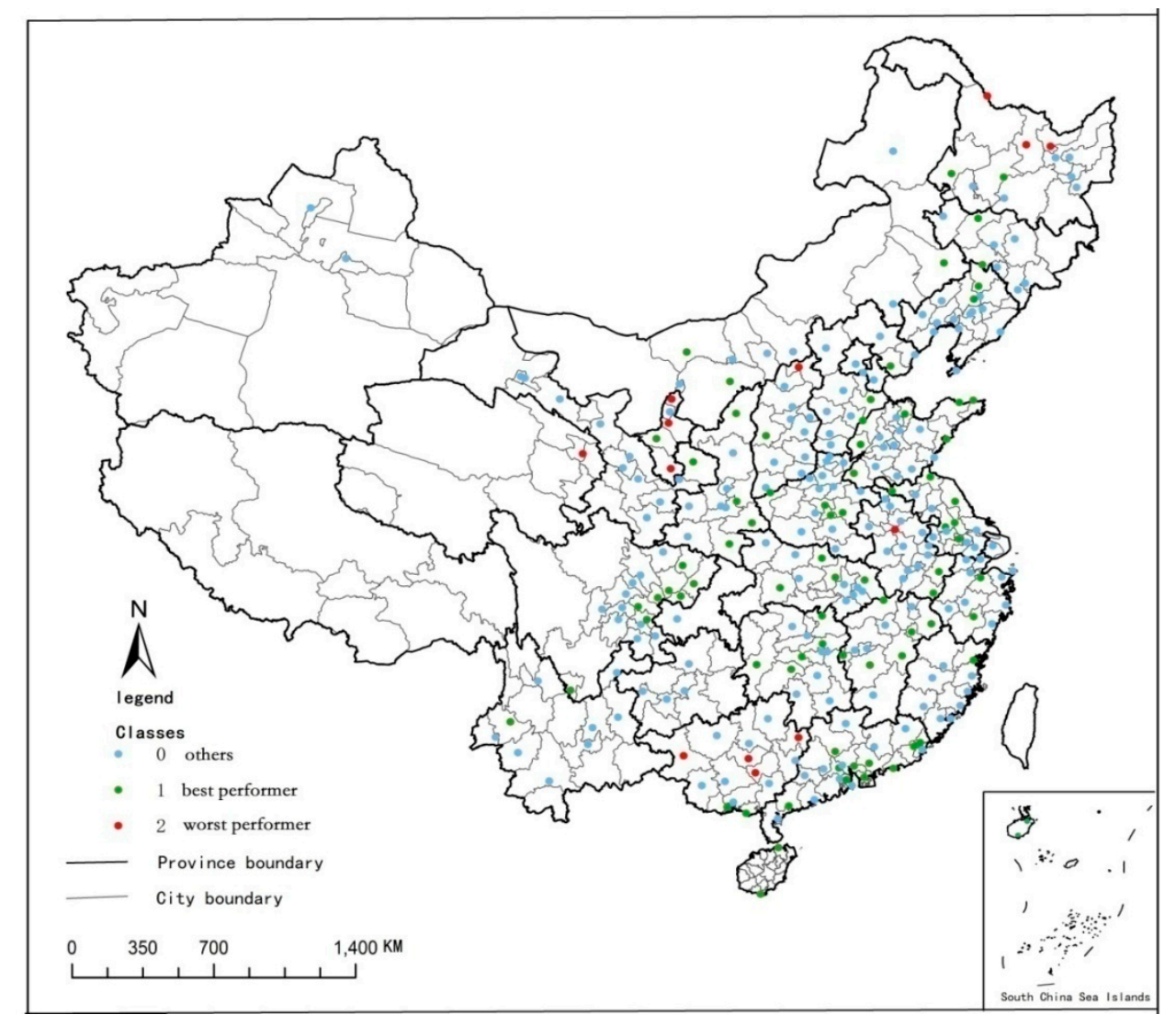

Figure 4. Distribution of best performers and worst performers. 


\subsubsection{Analysis of Dynamic Changes in Energy and Environmental Performance}

National Level

We examined dynamic changes in EEP and its decompositions by EEPI (calculated by Equations (14)-(16)). We first calculated the average value at the country level involving a five-year span of 283 cities' total performance changes and decompositions over temporal and spatial dimensions. The average EEP change, technical efficiency change, and technological change are $2.38 \%,-1.57 \%$ and $3.95 \%$, respectively (Table 3). That is to say, China made considerable progress in the energy conservation and emissions abatement in the study period. The Chinese government made great strides in environmental protection under the 12th five-year plan (FYP) (2011-2015), which focused on upgrading the industrial structure for low energy consumption and pollution reduction. Further, the industrial sectors comprised $57.2 \%$ of GDP in 2010 but only $47.1 \%$ in 2014 . Changes in technical efficiency continually declined with the exception of the period 2012-2013, whereas a slower and slower upward trend was observed in technological changes. In other words, EEP change is mainly driven by technological progress rather than technical efficiency improvement $[13,48,65]$. Government policies targeting the improvement of technical efficiency in the industrial sectors may indeed enhance overall environmental performance.

Table 3. Arithmetic mean of energy and environmental performance index (EEPI) and its decompositions for 283 cities.

\begin{tabular}{cccccc}
\hline Index & 2010-2011 & 2011-2012 & 2012-2013 & 2013-2014 & Average \\
\hline EEPI $I_{\text {total }}^{t, t+1}$ & 0.0004 & 0.0246 & 0.0634 & 0.0067 & 0.0238 \\
eff $h_{\text {total }}^{t, t+1}$ & -0.0969 & -0.0067 & 0.0579 & -0.0172 & -0.0157 \\
techch $_{\text {total }}^{t, t+1}$ & 0.0973 & 0.0313 & 0.0055 & 0.0239 & 0.0395 \\
\hline
\end{tabular}

Cities on the production frontier achieved rapid technological progress and made other cities more difficult to catch up with the production frontier. In other word, the decrease of technical efficiency is a relative deterioration caused by fast technological progress. The decline in technical efficiency is roughly consistent with observations previously made by Meng, Fan, Zhou and Zhou [65]. We further interpreted the deterioration of technical efficiency by assuming that a production activity with one energy input, one desirable output, and undesirable output can have reduced energy input and undesirable output while fixing desirable output as shown in Figure 5. The energy and environmental production technology can be represented by the energy and environmental input set:

$$
\mathbf{L}(y)=\{(e, b):(e, b) \text { can produce } y\}
$$

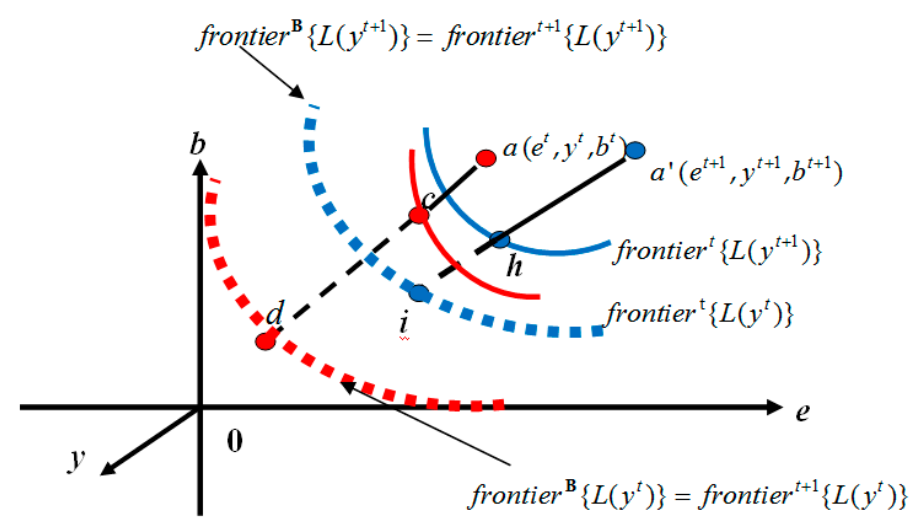

Figure 5. Deterioration of technical efficiency. 
Suppose that one production unit's activities are observed with two points $a\left(e^{t}, y^{t}, b^{t}\right)$ and $a^{\prime}\left(e^{t+1}, y^{t+1}, b^{t+1}\right)$ at periods " $t$ " and " $t+1$ " respectively. frontier ${ }^{t}$ represents the production frontier at period " $t$ ". frontier ${ }^{B}$ denotes the biennial production frontier of pooled observations from period " $t$ " and " $t+1$ ", and frontier ${ }^{B}$ could be completely determined by frontier ${ }^{t+1}$ which implies that frontier $^{B}=$ frontier $^{t+1}$. Considering $y^{t+1} \geq y^{t}$ with the coordinate $y$, production frontiers in blue lines (i.e., cross section with $y=y^{t+1}$ ) are higher than those in red lines (i.e., cross section with $y=y^{t}$ ) as a result of technological progress. We express the biennial Luenberger index as follows:

$$
\begin{aligned}
\operatorname{EEPI}_{B}{ }^{t, t+1} & =(a-d)-\left(a^{\prime}-i\right) \\
\text { effch }_{B}^{t, t+1} & =(a-c)-\left(a^{\prime}-i\right) \\
\text { techch }_{B}^{t, t+1} & =\{(a-d)-(a-c)\}-\left\{\left(a^{\prime}-i\right)-\left(a^{\prime}-i\right)\right\} \\
& =(c-d)
\end{aligned}
$$

Given $(a-c)<\left(a^{\prime}-i\right)$, as shown in Figure 5, the catch up effect becomes weak and the technical efficiency deteriorates, which indicates that relative deterioration occurs. However, considering $(a-d)>\left(a^{\prime}-i\right), a^{\prime}$ is closer to frontier $^{B}$ than $a$, which implies that the EEP for observed production activity improves from period " $t$ " and " $t+1$ ".

Table 4 shows the contributions of specific energy and undesirable output to the changes in total performance and sub-performances. Energy plays a more important role (contribution over 50\%) than undesirable outputs in total performance change and its four sub-performances. With respect to undesirable outputs, $\mathrm{SO}_{2}$ performance change has the strongest effect on total performance change $(25.36 \%)$ while the effect of soot emission performance change is the lowest $(0.80 \%)$. Technological change behaves similarly; $\mathrm{SO}_{2}$ technological change contributes more to total technological change (26.91\%) than soot technological change (4.15\%). Technical efficiency change shows much different characteristics. The contribution from wastewater technical efficiency change to total technical efficiency change was the smallest $(4.74 \%)$ while $\mathrm{SO}_{2}$ technical efficiency change made the largest contribution $(28.64 \%)$. In effect, $\mathrm{SO}_{2}$ has become the largest contributor to total performance change

\begin{tabular}{|c|c|c|c|c|c|}
\hline $\begin{array}{c}\text { Index } \\
\text { Average } \\
\text { Contribution }\end{array}$ & $\begin{array}{c}E E P I_{\text {total }}^{t, t+1} \\
0.0238 \\
100 \%\end{array}$ & $\begin{array}{c}E E P I_{\text {energy }}^{t, t+1} \\
0.0123 \\
51.01 \%\end{array}$ & $\begin{array}{c}E E P I_{S O 2}^{t, t+1} \\
0.0061 \\
25.36 \%\end{array}$ & $\begin{array}{c}E E P I_{\text {soot }}^{t, t+1} \\
-0.0002 \\
0.80 \%\end{array}$ & $\begin{array}{c}\text { EEPI } I_{\text {wastewater }}^{t, t+1} \\
0.0055 \\
22.83 \%\end{array}$ \\
\hline Index & effch $h_{\text {total }}^{t, t+1}$ & effch energy & eff $c h_{S O 2}^{t, t+1}$ & eff $c h_{\text {soot }}^{t, t+1}$ & eff $h_{\text {wastewater }}^{t, t+1}$ \\
\hline Average & -0.0157 & -0.0086 & -0.0045 & -0.0018 & -0.0007 \\
\hline Contribution & $100 \%$ & $54.97 \%$ & $28.64 \%$ & $11.65 \%$ & $4.74 \%$ \\
\hline Index & techch total & techch energy & techch $_{\mathrm{SO2} 2}^{t, t+1}$ & techch ${ }_{\text {soot }}^{t, t+1}$ & techch $h_{\text {wastewater }}^{t, t+1}$ \\
\hline Average & 0.0395 & 0.0210 & 0.0106 & 0.0016 & 0.0063 \\
\hline Contribution & $100 \%$ & $53.09 \%$ & $26.91 \%$ & $4.15 \%$ & $15.85 \%$ \\
\hline
\end{tabular}
and sub-performance changes among the three undesirable outputs.

Table 4. Contributions of specific energy and undesirable output to total performance change, sub-performance changes.

Regional Level

China can be divided into four areas by economic development levels and geographical characteristics: eastern, northeastern, central, and western areas. Urban agglomeration, considered to be an economic growth point, leads regional economic development. We explored the regional differences in urban agglomeration accordingly. The ten agglomerations we observed include Beijing-Tianjin-Hebei, the central and southern of Liaoning province, the Yangtze River Delta, the western side of the Taiwan Strait, the Shandong Peninsula, the Central Plain, the middle Yangtze River, the Pearl River Delta, Sichuan and Chongqing, and the Central Shaanxi Plain [66,67]. 
Table 5 shows the average changes in EEPI and its decompositions among the four areas for every two consecutive years. The average changes in EEP are positive indicating a marked improvement in the four areas over the study period. The central area shows the most significant performance improvement $(2.97 \%)$, followed by the eastern $(2.73 \%)$ and western $(1.96 \%)$ areas. The northeastern area experienced almost no EEP change (0.50\%). Heavy industry renders the northeastern area less able to improve its EEP. We also found that the eastern area achieved the greatest technological progress $(5.86 \%)$ while experiencing the greatest decline in technical efficiency $(-3.14 \%)$ among the four areas; technological progress in the eastern area makes a greater contribution to performance improvement, which substantially offsets the deterioration of technical efficiency.

Table 5. Arithmetic means for EEPI total $I^{t, t+1}$ eff $\mathrm{fh}_{\text {total }}^{t, t+1}$ and $t e c h c h_{\text {total }}^{t, t+1}$ in 2010-2014 among four areas.

\begin{tabular}{|c|c|c|c|}
\hline Arithmetic Mean & $E E P I_{\text {total }}^{t, t+1}$ & effch total & techch ${ }_{\text {total }}^{t, t+1}$ \\
\hline East & 0.0273 & -0.0314 & 0.0586 \\
\hline Central & 0.0297 & -0.0081 & 0.0378 \\
\hline West & 0.0196 & -0.0032 & 0.0228 \\
\hline Northeast & 0.0050 & -0.0215 & 0.0264 \\
\hline
\end{tabular}

We next compared the effects of specific energy and undesirable output on the changes in total performance and sub-performances in the four areas and ten urban agglomerations. Figure 6 shows the contributions from specific energy and undesirable outputs to total performance change among four areas and ten urban agglomerations. Energy contribution rates in the eastern (50.93\%), central $(51.79 \%)$, and northeastern $(88.20 \%)$ areas explain more than half of the performance improvement but less so in the western area $(45.38 \%)$. Most sub-performances in the four areas were improved. Soot emission performance declined in eastern and northeastern areas over 2010-2014, likely because the environmental regulation for soot emissions was eased during the study period despite the truth that severe haze happened frequently in China. In the 10th FYP period, the central government placed quantified constraints on soot emission which were canceled in the 11th and 12th FYP periods; the top priority for the central government with mixed environmental regulations was to curb excessive emissions of $\mathrm{SO}_{2}$ and $\mathrm{NO}_{\mathrm{x}}$.

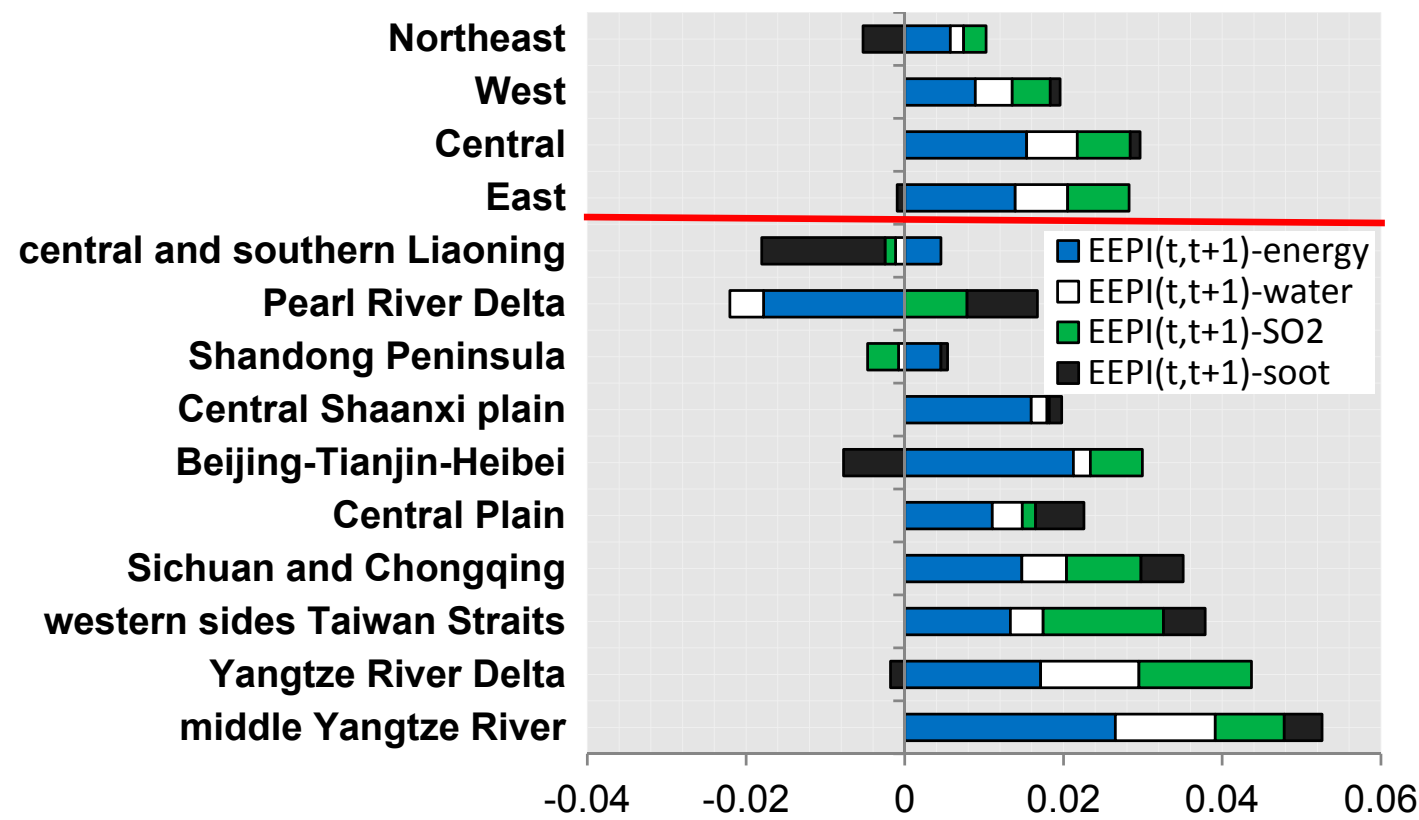

Figure 6. Contributions of specific energy and undesirable outputs performance to total performance among four areas and ten urban agglomerations. 
Energy is apparently the major driving force for improving total performance in the Beijing-Tianjin-Hebei region, where energy accounts for $95.68 \%$ of the improvement in total performance. Energy contributed $80.64 \%$ to the improvement in total performance in the central Shaanxi plain, which is an important coal base in China. Most urban agglomerations achieved significant improvement in total performance during 2010-2014, especially the middle Yangtze River. Total performance declined in the central and southern Liaoning province, however, due to the deterioration in soot emission performance. Total performance in the Pearl River Delta also declined due to a rapid increase in energy consumption.

Figure 7 shows contributions from specific energy and undesirable outputs to the total technical efficiency change among the four areas and ten urban agglomerations. Total technical efficiency decreased significantly in all four regions. Deterioration in energy technical efficiency is the root cause of decline in total technical efficiency in the four areas with exception of the central area, which is defined by a decrease in $\mathrm{SO}_{2}$ technical efficiency (elsewhere the second-most important cause of decline). Technical efficiency in most urban agglomerations decreased continually from 2010 to 2014 . Only the middle Yangtze River area and central Shaanxi plain made progress in technical efficiency, which can be attributed to improvements in energy efficiency.

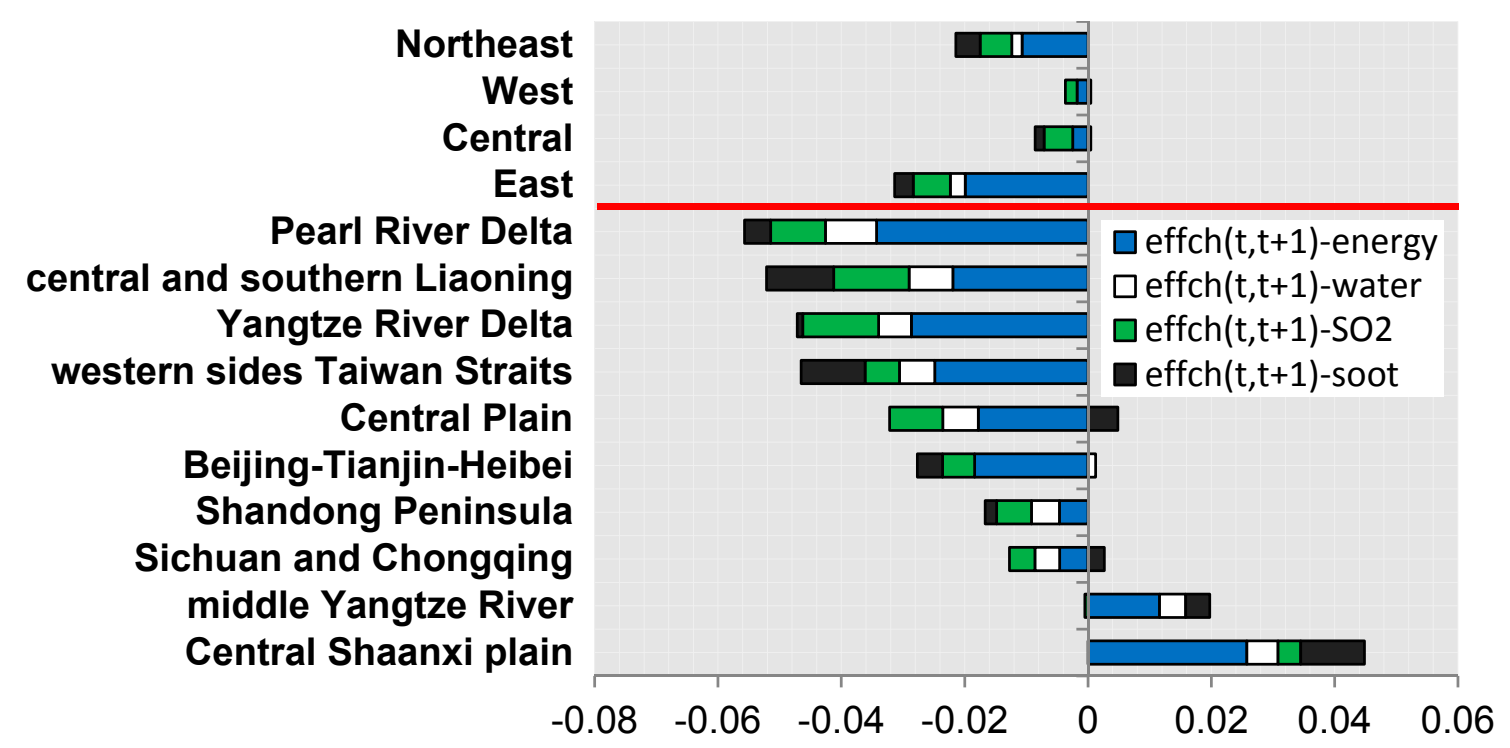

Figure 7. Contributions of specific energy and undesirable outputs to total technical efficiency among four areas and ten urban agglomerations.

Figure 8 shows the contributions of specific energy and undesirable outputs to total technological change among the four areas and ten urban agglomerations. Energy contributed more significantly than the sum of undesirable outputs in the total technological change in the four areas; $\mathrm{SO}_{2}$ technology was markedly improved while soot technology only slightly so. Technical progress in almost all ten urban agglomerations (except the central Shaanxi) grew continually. Total technological change in the central Shaanxi area declined $2.5 \%$ on average due to the bad performance of best performers around the central Shaanxi area. 


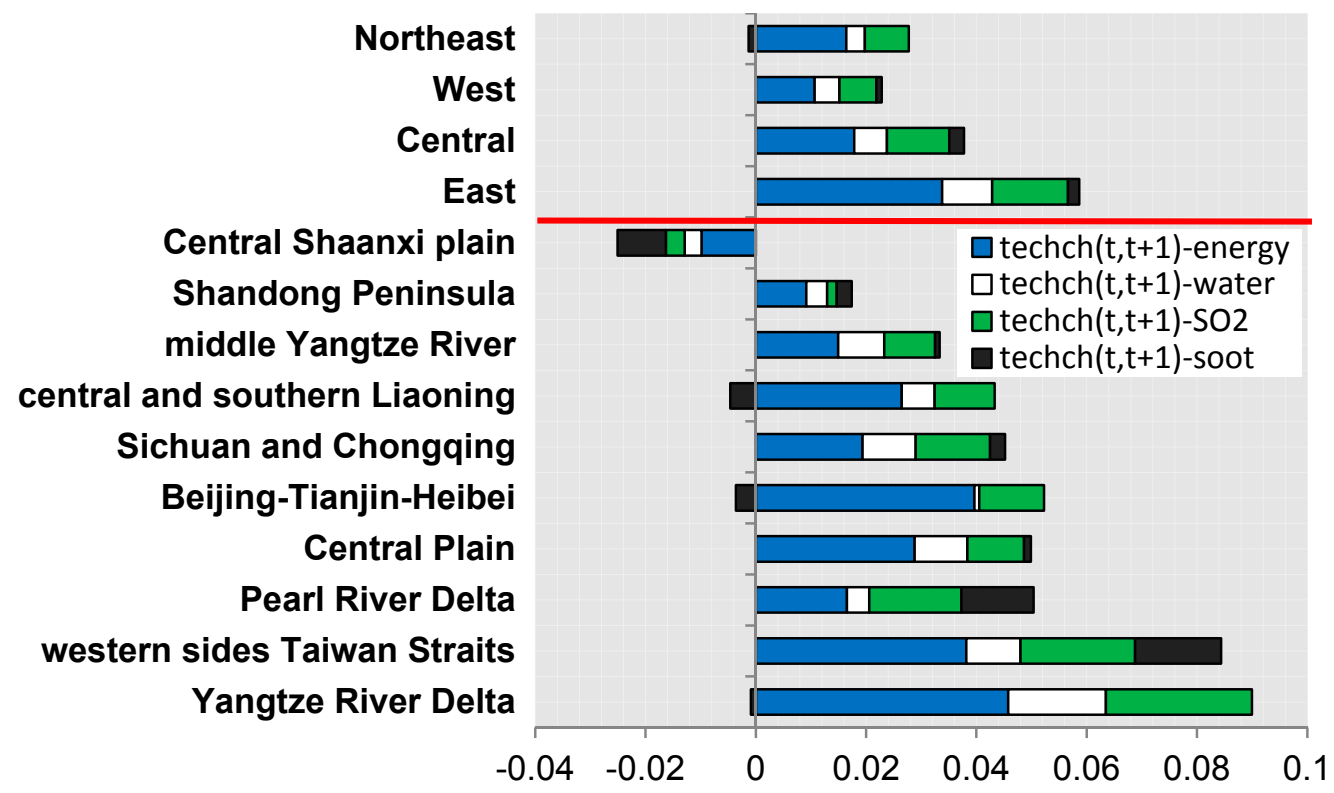

Figure 8. Contributions of specific energy and undesirable outputs to total technological change among four areas and ten urban agglomerations.

3.2.3. Analysis of Spatial Distribution Evolution on Energy and Environmental Performance Potential

\section{EEP Spatial Pattern}

Figure 9 shows the changes in global Moran's $I_{g}$ of EEP during 2010-2014. The average value of global Moran's $I_{g}$ is 0.0807 , indicating a positive spatial correlation. The positive difference in EEP spatial distribution increases along with the decline of global Moran's $I_{g}$.

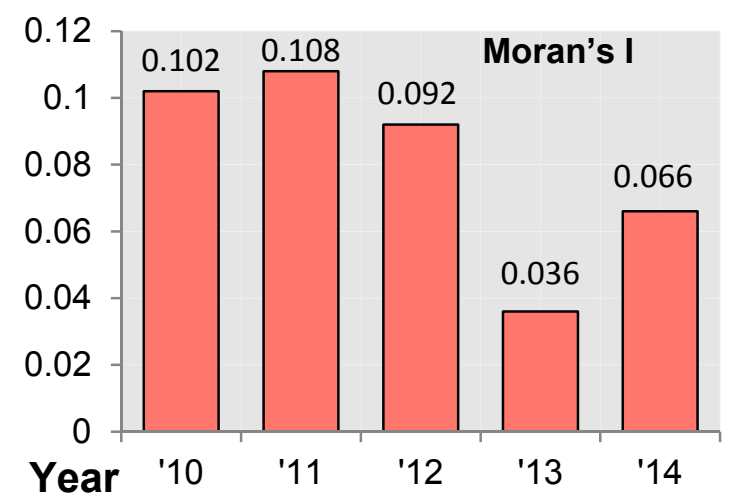

Figure 9. Changes in global Moran's $I_{g}$ of EEP.

We used a LISA cluster map based on the local Moran's $I_{l}$ to observe the spatial agglomeration effects, i.e., whether a spatial unit shows a spatial correlation with its neighbors or not (Figure 10). There is significant agglomeration effect evidenced by four types of spatial correlations: high-high, low-low, low-high (middle is low and surroundings are high) and high-low (middle is high and surroundings are low). The high-high type mainly exists in the Huanghe Delta and the developed southeast coast of China in 2010. The high-high type areas spread from the developed southeast coast to the areas with high ecological quality, such as the northern border between Sichuan and Hubei provinces (which have a famous giant panda habitat called the Shennongiia National Nature Reserve) or the Dongting lake basin (the third-largest lake in China renowned for its beautiful scenery in the north of Hunan province); China's second largest lake, Poyang, is located in the northern 
Jiangxi province with a forest acreage over $60 \%$; the Huanghe Delta and Yangtze River Delta similarly have rich wetland resources which maintain the high-high cluster characteristics resulting from their inherently high ecological quality. Cities with high ecological quality, especially those with national nature reserves, wetlands and forests, most commonly feature high-high type correlations.

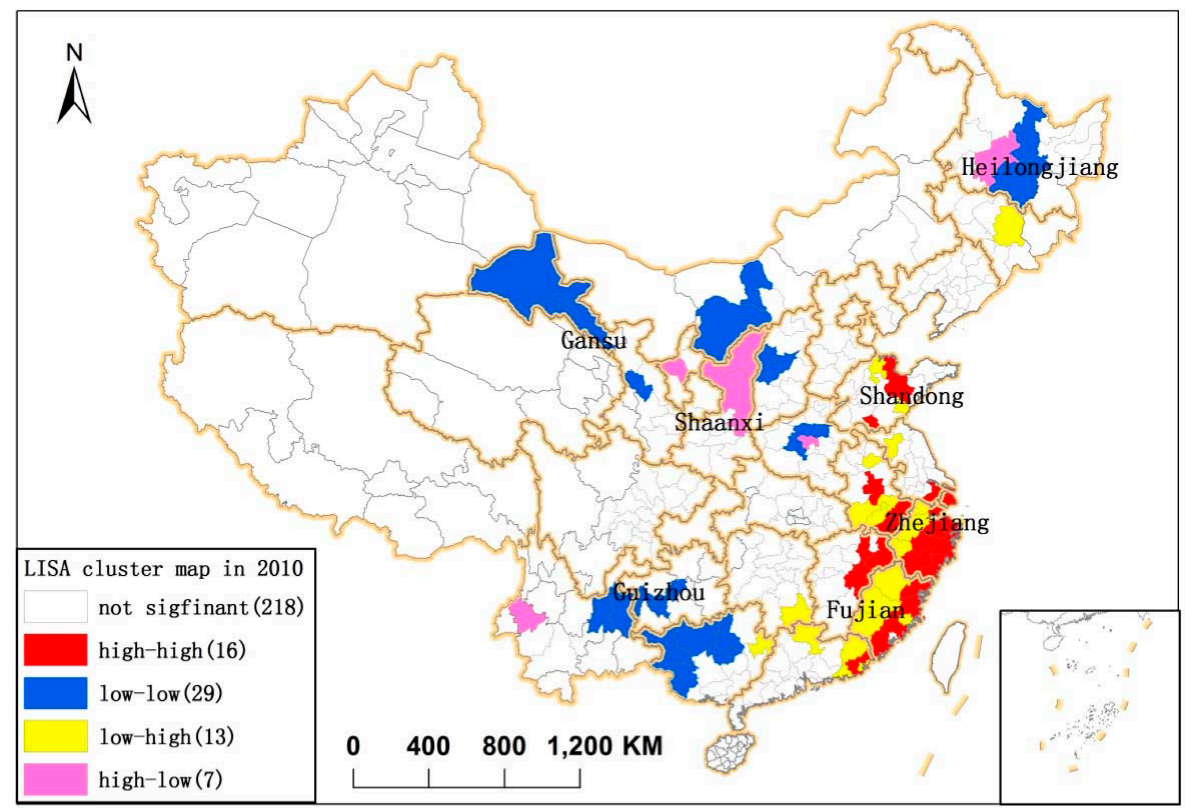

(a)

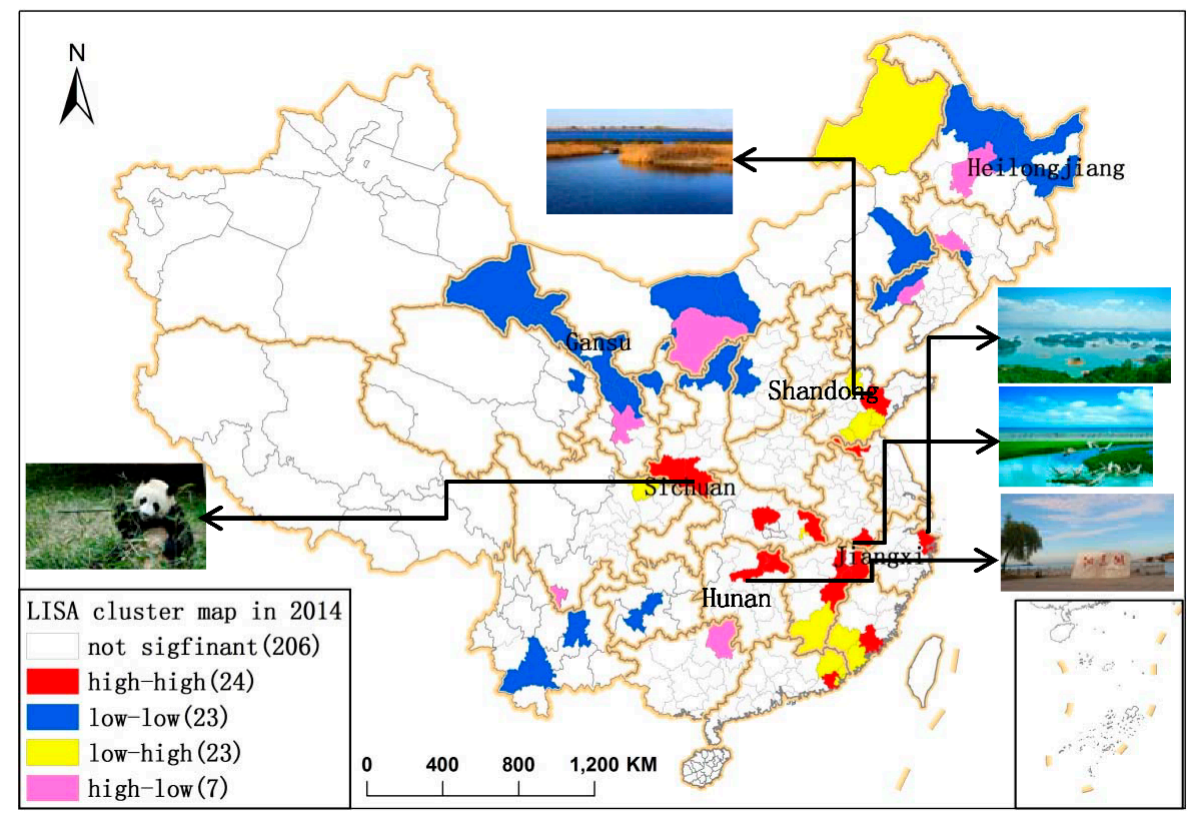

(b)

Figure 10. Local indicators of spatial association (LISA) cluster map of EEP in 2010 and 2014. (a) LISA cluster map in 2010; (b) LISA cluster map in 2014.

Influencing Factors on Energy and Environmental Performance Potential

Considering the spatial heterogeneity, we used the GWR method instead of the ordinary (global) linear regression to capture influencing factors on EEP potential with the aim to reveal its spatially varying links. Energy is positively correlated with pollutants because pollutants mainly originate in the combustion of energy sources. Energy conservation potential and $\mathrm{SO}_{2}$ emission abatement 
potential exhibit similar distribution characteristics for this reason. In this study, we focused on the influencing factors of $\mathrm{SO}_{2}$ emission abatement potential:

$$
\text { Potential }_{\mathrm{SO}_{2}}=D_{\mathrm{SO}_{2}}^{t}\left(\mathbf{x}^{\mathrm{t}}, \mathbf{e}^{\mathbf{t}}, \mathbf{y}^{\mathrm{t}}, \mathbf{b}^{\mathrm{t}} ; \mathbf{g}\right) \times \mathrm{SO}_{2} \text { Emission }
$$

We used three key factors to interpret the change in $\mathrm{SO}_{2}$ emission abatement potential: gross industrial output, pollution intensity, and industrial structure. Here, the ratio of $\mathrm{SO}_{2}$ emission to gross industrial output represents pollution intensity; the industrial structure is measured by the share of GDP of the service industry $[45,68,69]$. The following GWR model was used to investigate the effects of various influencing factors on $\mathrm{SO}_{2}$ emission abatement potential:

$$
\text { Potential }_{S O_{2} i}=\beta_{0}\left(u_{i}, v_{i}\right)+\beta_{1}\left(u_{i}, v_{i}\right) G I O_{i}+\beta_{2}\left(u_{i}, v_{i}\right) S I_{i}+\beta_{3}\left(u_{i}, v_{i}\right) S R_{i}+\varepsilon_{i}
$$

where $\beta$ denotes the coefficient parameter; $\varepsilon$ is a random error term; GIO denotes the gross industrial output; $S R$ denotes the share of GDP of the service industry; SI represents $\mathrm{SO}_{2}$ pollution intensity.

As shown in Table 6, Model (32) passes the $1 \%$ level significance test. The $R^{2}$ indicator of goodness of fit is $0.67\left(R^{2}\right.$ in global regression result is 0.20$)$, which is fairly high. The range of local $R^{2}$ is between 0.36 and 0.9 .

Table 6. Overall fitting results GWR model based on $\mathrm{SO}_{2}$ emission abatement potential.

\begin{tabular}{cc}
\hline Indicator & $\mathrm{SO}_{\mathbf{2}}$ Emission Abatement Potential \\
\hline local $R^{2}$ & $0.36-0.90$ \\
$R^{2}$ & 0.67 \\
adjusted $R^{2}$ & 0.57 \\
residual sum of squares & $5.17 \times 10^{10}$ \\
AICc & 6322 \\
$\mathrm{~F}$ & 4.84 \\
probability & 0.003 \\
\hline
\end{tabular}

Figure 11a-c shows the spatial distribution of influencing factors that affect $\mathrm{SO}_{2}$ emission abatement potential. The natural breaks (Jenks) method was used to split the regression coefficient into four categories to ensure scientific geographical results. In most cities, the gross industrial output shows a positive effect on $\mathrm{SO}_{2}$ emission abatement potential. Cities with larger gross industrial output need to consume more energy and are thus inclined to emit more $\mathrm{SO}_{2}$. The strongest impact coefficients of gross industrial output are distributed in the western parts of the country. The effects of gross industrial output on $\mathrm{SO}_{2}$ emission abatement potential also show a significant downtrend from the western interior to the eastern coast. Pollution intensity is also correlated with $\mathrm{SO}_{2}$ emission abatement potential, because cities with higher pollution intensity produce more pollutants. Heavy industry accounts for a considerable proportion of industrial sectors in areas around the Bohai Gulf. Cities in the Shandong Peninsula, central and southern Liaoning province, and Beijing-Tianjin-Hebei showed the strongest pollution intensity in terms of $\mathrm{SO}_{2}$ emission abatement potential (i.e., areas around the Bohai Gulf where severe haze is relatively common [70-72]).

The ratio of the service industry to GDP shows an uncertain effect on $\mathrm{SO}_{2}$ emission abatement potential. We next examined the correlation between the ratio of the service industry to GDP and $\mathrm{SO}_{2}$ emission abatement potential with standardized $z$-scores, as shown in Figure 12. The Pearson correlation between them is pretty weak (0.119). Only 37 (55) cities pass the significance tests at $5 \%(10 \%)$ level among all 283 cities. This suggests that industrial structure is not the significant influencing factor of $\mathrm{SO}_{2}$ emission abatement potential during our study period. In fact, improvements to industrial structure caused by relatively fast growth in the service industry do not significantly reduce $\mathrm{SO}_{2}$ emissions. Although the ratio of industrial sectors to GDP is decreasing on the whole, the ever-increasing value added by the industrial sectors increases $\mathrm{SO}_{2}$ emissions and leaves 
considerable room for emission abatement. This phenomenon is more common in developed cities, like Shanghai or cities in Jiangsu and Zhejiang provinces. He, et al. [73] and $\mathrm{Hu}$, et al. [74] similarly found that industrial structure does not significantly affect industrial pollution at the city level in China.

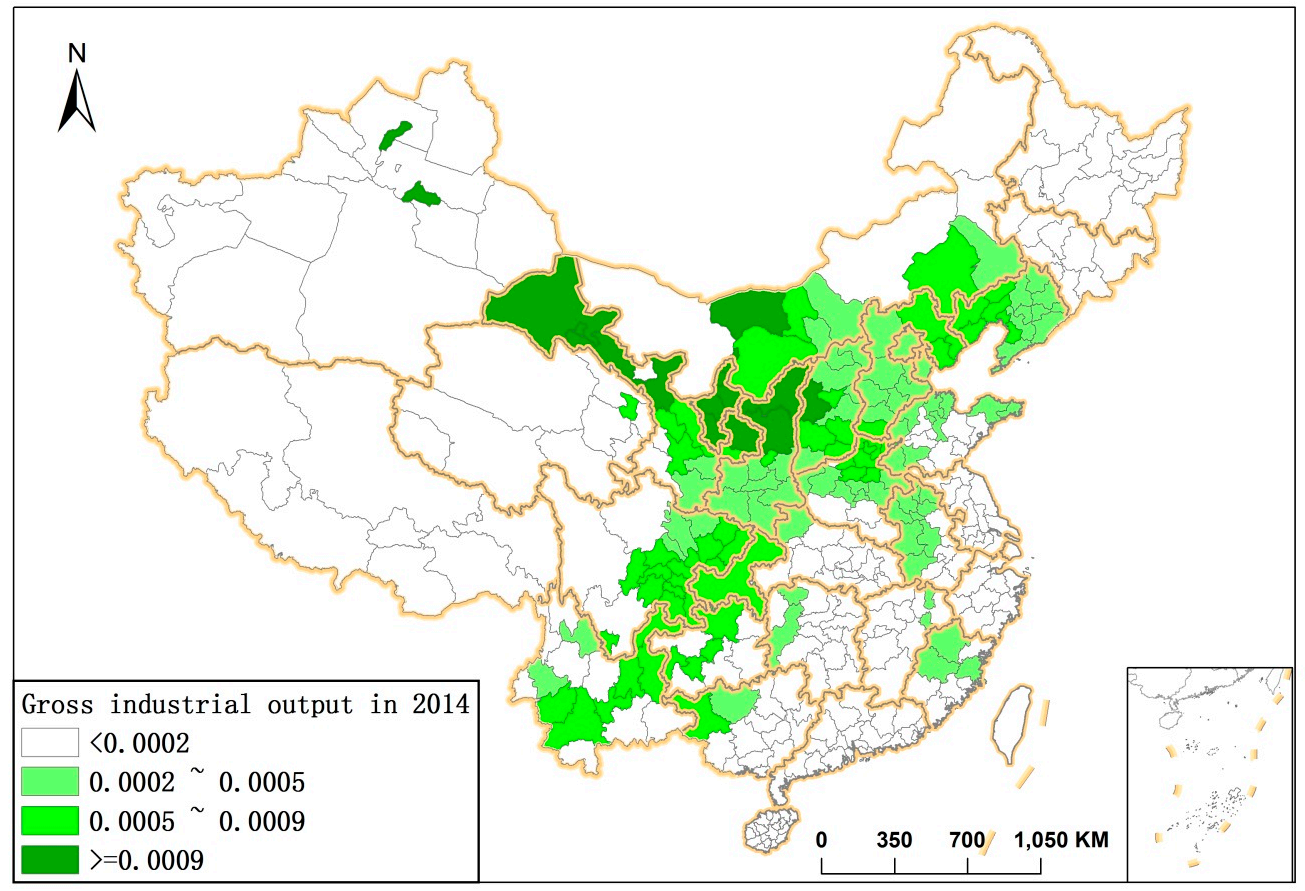

(a)

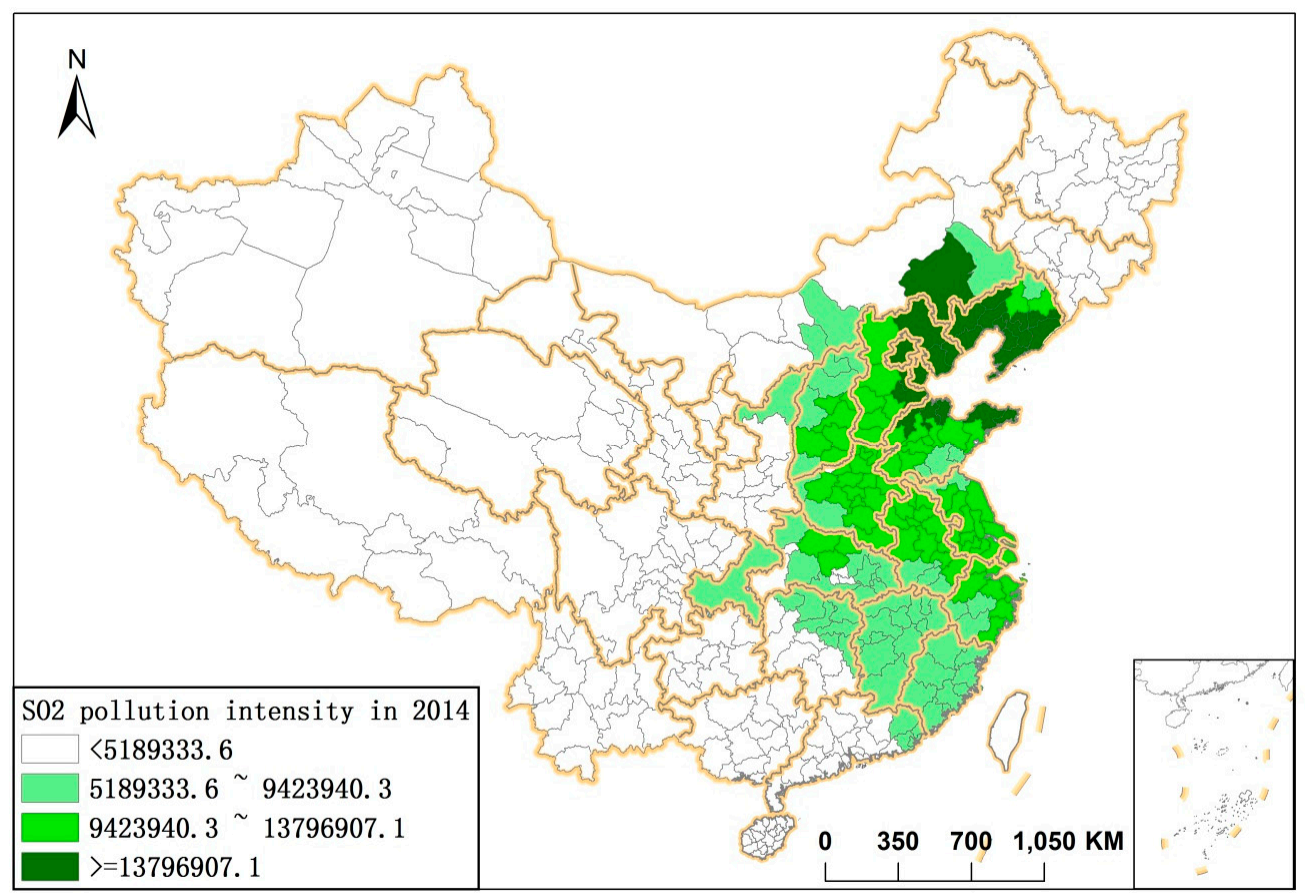

(b)

Figure 11. Cont. 


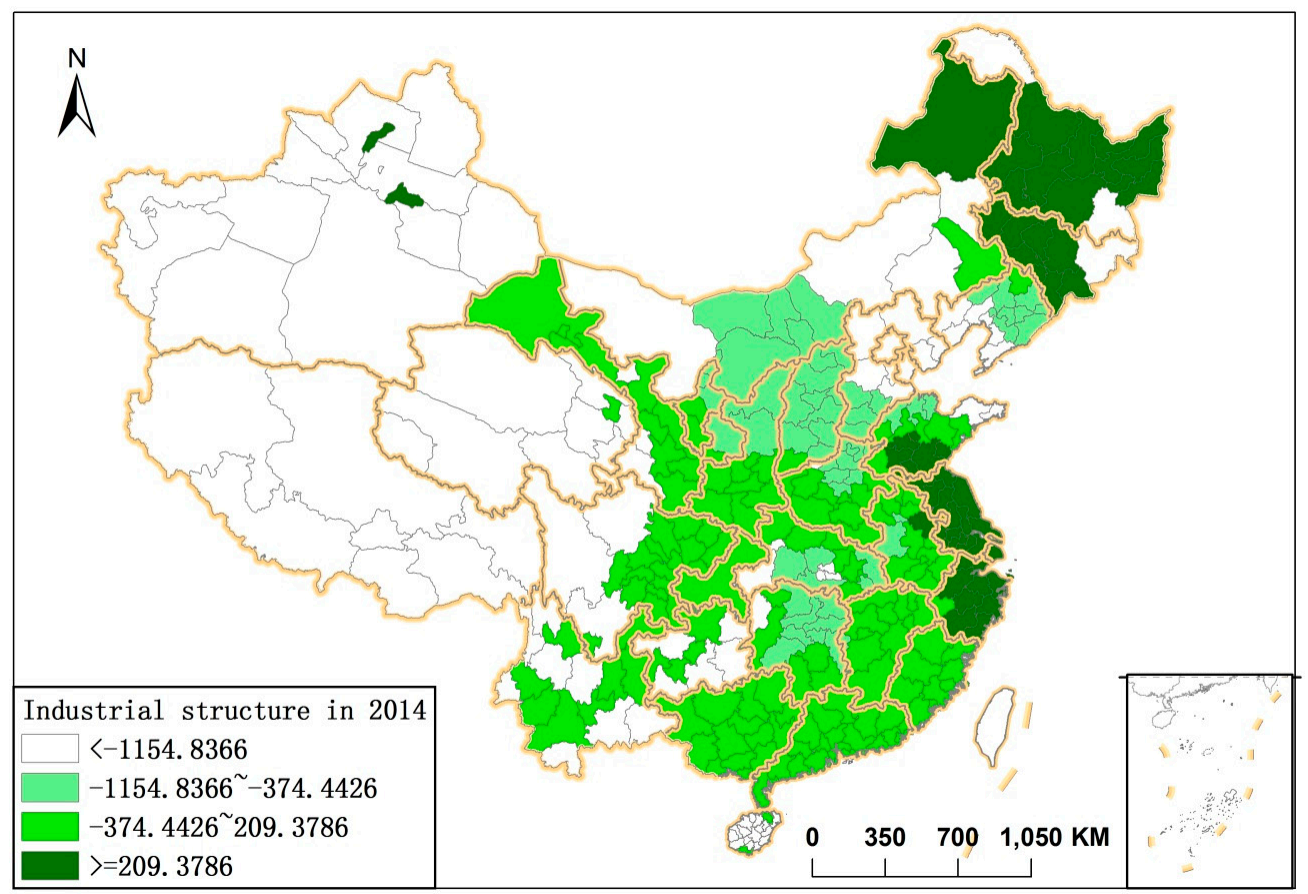

(c)

Figure 11. Local geographically weighted regression (GWR) estimates of influencing factors for $\mathrm{SO}_{2}$ emission abatement potential in 2014. (a) Regression coefficient of gross industrial output; (b) Regression coefficient of $\mathrm{SO}_{2}$ pollution intensity; (c) Regression coefficient of industrial structure.

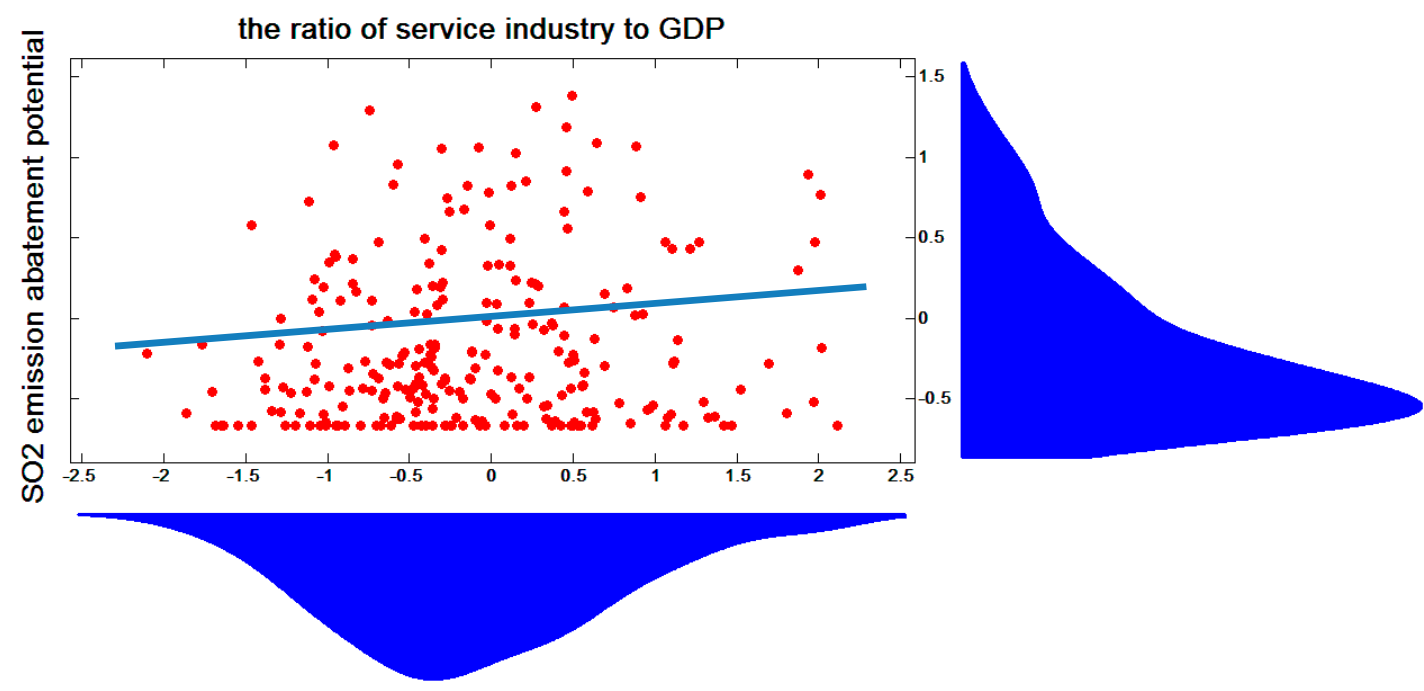

Figure 12. Correlation between ratio of service industry to GDP and $\mathrm{SO}_{2}$ emission abatement potential.

\section{Conclusions}

China is currently facing a trade-off between economic development and environmental protection. Chinese cities represent complete, independent administrative districts which implement environmental regulations; top administrators are held accountable for environmental damages. A given city's energy utilization and environment regulation directly influence the amount to which it pollutes the environment, and to identify the best performer and regional difference on EEP will stimulate the cities to learn from each other. This paper proposed a new biennial Luenberger EEPI 
to avoid infeasibility problem in conducting data envelopment analysis. Changes in EEP were decomposed into technical efficiency change and technological change. To examine the contributions of specific undesirable outputs (e.g., $\mathrm{SO}_{2}$, soot, and wastewater) and energy inputs to the EEP, the total performance was divided into sub-performances via a non-radial measure. We empirically analyzed a sample of 283 cities from 2010 to 2014 accordingly and investigated the primary drivers of emission abatement potential based on the GWR model. Our main conclusions can be summarized as follows.

(1) The best performers are mainly located in the Guangdong, Shandong, Jiangsu, Jiangxi, Sichuan, and Hainan provinces, while the worst performers are mainly distributed in Heilongiiang, Guangxi, Ningxia, and Shanxi provinces. The best performers possess advanced service industries and either consume less energy or have inherently high ecological quality, while the worst performers depend on abundant coal and nonferrous metal resources to support economic development. Best performers tended to move from the coastal towards the inland area over time.

(2) At the national level, average EEP change, technical efficiency change, and technological change values are $2.38 \%,-1.57 \%$, and $7.90 \%$, respectively. China achieved remarkable progress in energy conservation and emission abatement over the study period. The deterioration of the technical efficiency is a relative deterioration caused by the fast technological progress. Changes in EEP are primarily attributable to technological progress, but said progress slowed down during the study period.

(3) At the regional level, the central area $(2.97 \%)$ shows the greatest improvement in total performance followed by eastern $(2.73 \%)$ and western $(1.96 \%)$ areas. The northeastern area $(0.50 \%)$ shows almost no change in EEP. The eastern area achieves the greatest technological progress $(5.86 \%)$ but greatest decline in technical efficiency $(-3.14 \%)$ among the four areas. The sub-performances all increased apart from soot emission performance. Deterioration in $\mathrm{SO}_{2}$ technical efficiency is the biggest driver of deteriorated technical efficiency in all four areas.

We used the ESDA method to find that EEP has obvious spatial agglomeration features. The high-high type clusters mainly exist in Shandong province and the southeast coast of China; high-high type clusters move from coastal areas towards the inland areas which have inherently better ecological quality. The factors that affect $\mathrm{SO}_{2}$ emission abatement potential exhibit significant spatial heterogeneity in different areas. The gross industrial output positively affects $\mathrm{SO}_{2}$ emission abatement potential in most cities. The strongest impact coefficients of gross industrial output are mainly distributed in the western area. Cities with the strongest positive effect of pollution intensity on $\mathrm{SO}_{2}$ emission abatement potential were mainly distributed in central and southern Liaoning province, Beijing-Tianjin-Hebei, and Shandong Peninsula areas (i.e., areas around the Bohai Gulf which are characterized by haze problems). The ratio of service industry to GDP has an uncertain effect on $\mathrm{SO}_{2}$ emission abatement potential, indicating that industrial structure is not the significant influencing factor of $\mathrm{SO}_{2}$ emission abatement potential in the study period.

Based on the empirical results, we make the following policy recommendations: First, the measurement of EEP is useful for the Chinese government to build an evaluation system of EEP of the industrial sectors at the city level. Second, the Chinese government should pay more attention to the cities with the worst EEP that have abundant mineral resources and encourage these cities to develop resource-processing industries then they can produce high value-added products instead of raw materials. Third, Cities that possess advanced service industries or have inherently high ecological quality achieve a high EEP. Therefore, the city government should encourage the development of service industry with low energy consumption and low pollution. Besides, they should pay attention to protecting ecological environment and avoiding the path of "pollution first, treatment later". Fourth, the Chinese government should promote the exchange of advanced experience and technology relating to energy conservation and emission abatement in order to narrow the EEP gaps between different cities.

Author Contributions: This work was designed, analyzed, and written by the both authors. The data were gathered by the corresponding author. 
Funding: This research was funded by the National Natural Science Foudation of China (Grant number 71704095).

Acknowledgments: The author sincerely appreciates the academic editors and three anonymous reviewers for their helpful comments and thoughtful suggestions used to help us improve the quality of our manuscript.

Conflicts of Interest: The authors declare no conflict of interest

\section{References}

1. Song, M.; Wang, S.; Yu, H.; Yang, L.; Wu, J. To reduce energy consumption and to maintain rapid economic growth: Analysis of the condition in China based on expended IPAT model. Renew. Sustain. Energy Rev. 2011, 15, 5129-5134. [CrossRef]

2. British Peroleum Company. BP Statistical Review of World Energy 2017; British Peroleum Company: London, UK, 2017; Available online: https://www.bp.com/en/global/corporate/media/speeches/bpstatistical-review-of-world-energy-2017.html (accessed on 28 June 2017).

3. Chen, J.; Song, M.; Xu, L. Evaluation of environmental efficiency in China using data envelopment analysis. Ecol. Indic. 2015, 52, 577-583. [CrossRef]

4. Huang, R.-J.; Zhang, Y.; Bozzetti, C.; Ho, K.-F.; Cao, J.-J.; Han, Y.; Daellenbach, K.R.; Slowik, J.G.; Platt, S.M.; Canonaco, F. High secondary aerosol contribution to particulate pollution during haze events in China. Nature 2014, 514, 218-222. [CrossRef] [PubMed]

5. Gao, J.; Woodward, A.; Vardoulakis, S.; Kovats, S.; Wilkinson, P.; Li, L.; Xu, L.; Li, J.; Yang, J.; Cao, L.; et al. Haze, public health and mitigation measures in China: A review of the current evidence for further policy response. Sci. Total Environ. 2017, 578, 148-157. [CrossRef] [PubMed]

6. Ministry of Ecology and Environmental of the People's Repuclic of China. Report on the State of China's Environment in 2016; Ministry of Ecology and Environmental of the People's Republic of China: Beijing, China, 2016. Available online: http://www.zhb.gov.cn/hjzl/zghjzkgb/lnzghjzkgb/ (accessed on 28 June 2018).

7. Lepeule, J.; Schwartz, J. Chronic exposure to fine particles and mortality: An extended follow-up of the Harvard Six Cities study from 1974 to 2009. Environ. Health Perspect. 2012, 120, 965-970. [CrossRef] [PubMed]

8. Lepeule, J.; Bind, M.A.; Baccarelli, A.A.; Koutrakis, P.; Tarantini, L.; Litonjua, A.; Sparrow, D.; Vokonas, P.; Schwartz, J.D. Epigenetic influences on associations between air pollutants and lung function in elderly men: The normative aging study. Environ. Health Perspect. 2014, 122, 566-572. [CrossRef] [PubMed]

9. Farrell, M.J. The Measurement of Productive Efficiency. J. R. Stat. Soc. 1957, 120, 253-290. [CrossRef]

10. Charnes, A.; Cooper, W.W.; Rhodes, E. Measuring the efficiency of decision-making units. Eur. J. Oper. Res. 1978, 2, 429-444. [CrossRef]

11. Kuosmanen, T.; Kortelainen, M. Measuring Eco-efficiency of Production with Data Envelopment Analysis. J. Ind. Ecol. 2005, 9, 59-72. [CrossRef]

12. Hu, J.L.; Wang, S.C. Total-factor energy efficiency of regions in China. Energy Policy 2006, 34, $3206-3217$. [CrossRef]

13. Song, M.; Yang, L.; Wu, J.; Lv, W. Energy saving in China: Analysis on the energy efficiency via bootstrap-DEA approach. Energy Policy 2013, 57, 1-6. [CrossRef]

14. Özkara, Y.; Atak, M. Regional total-factor energy efficiency and electricity saving potential of manufacturing industry in Turkey. Energy 2015, 93, 495-510. [CrossRef]

15. Feng, C.; Wang, M. Analysis of energy efficiency and energy savings potential in China's provincial industrial sectors. J. Clean. Prod. 2017, 164, 1531-1541. [CrossRef]

16. Zhou, D.Q.; Wu, F.; Zhou, X.; Zhou, P. Output-specific energy efficiency assessment: A data envelopment analysis approach. Appl. Energy 2016, 177, 117-126. [CrossRef]

17. Honma, S.; Hu, J.L. Total-factor energy productivity growth of regions in Japan. Energy Policy 2009, 37, 3941-3950. [CrossRef]

18. Wang, Q.W.; Zhou, D.Q. An empirical study on the change of total factor energy efficiency in China. Syst. Eng. 2008, 26, 74-80. (In Chinese)

19. Chang, T.P.; Hu, J.L. Total-factor energy productivity growth, technical progress, and efficiency change: An empirical study of China. Appl. Energy 2010, 87, 3262-3270. [CrossRef]

20. Zhang, X.P.; Cheng, X.M.; Yuan, J.H.; Gao, X.J. Total-factor energy efficiency in developing countries. Energy Policy 2011, 39, 644-650. [CrossRef] 
21. Färe, R.; Grosskopf, S.; Lovell, C.A.K.; Pasurka, C. Multilateral productivity comparisons when some outputs are undesirable: A nonparametric approach. Rev. Econ. Stat. 1989, 71, 90-98. [CrossRef]

22. Kortelainen, M. Dynamic environmental performance analysis: A Malmquist index approach. Ecol. Econ. 2008, 64, 701-715. [CrossRef]

23. Zhou, P.; Ang, B.W.; Poh, K.L. Measuring environmental performance under different environmental DEA technologies. Energy Econ. 2008, 30, 1-14. [CrossRef]

24. Zhang, N.; Choi, Y. Total-factor carbon emission performance of fossil fuel power plants in China: A metafrontier non-radial Malmquist index analysis. Energy Econ. 2013, 40, 549-559. [CrossRef]

25. Rashidi, K.; Saen, R.F. Measuring eco-efficiency based on green indicators and potentials in energy saving and undesirable output abatement. Energy Econ. 2015, 50, 18-26. [CrossRef]

26. Sueyoshi, T.; Goto, M. Environmental assessment on coal-fired power plants in U.S. north-east region by DEA non-radial measurement. Energy Econ. 2015, 50, 125-139. [CrossRef]

27. Xie, B.C.; Duan, N.; Wang, Y.S. Environmental efficiency and abatement cost of China's industrial sectors based on a three-stage data envelopment analysis. J. Clean. Prod. 2016, 153, 626-636. [CrossRef]

28. Molinos-Senante, M.; Maziotis, A.; Sala-Garrido, R. The Luenberger productivity indicator in the water industry: An empirical analysis for England and Wales. Util. Policy 2014, 30, 18-28. [CrossRef]

29. Managi, S. Luenberger and Malmquist productivity indices in Japan, 1955-1995. Appl. Econ. Lett. 2003, 10, 581-584. [CrossRef]

30. Mahlberg, B.; Sahoo, B.K. Radial and non-radial decompositions of Luenberger productivity indicator with an illustrative application. Int. J. Prod. Econ. 2011, 131, 721-726. [CrossRef]

31. Azad, M.A.S.; Ancev, T. Measuring environmental efficiency of agricultural water use: A Luenberger environmental indicator. J. Environ. Manag. 2014, 145, 314-320. [CrossRef] [PubMed]

32. Wang, K. Evaluation and decomposition of energy and environmental productivity change using DEA. In Handbook of Operations Analysis Using Data Envelopment Analysis; Hwang, S.N., Lee, H.S., Zhu, J., Eds.; Springer: Berlin, Germany, 2016; pp. 207-297.

33. Wang, K.; Wei, Y.M. Sources of energy productivity change in China during 1997-2012: A decomposition analysis based on the Luenberger productivity indicator. Energy Econ. 2016, 54, 50-59. [CrossRef]

34. Xian, Y.; Huang, Z. Sources of carbon productivity change: A decomposition and disaggregation analysis based on global Luenberger productivity indicator and endogenous directional distance function. Ecol. Indic. 2016, 66, 545-555.

35. Wang, K.; Wei, Y.M.; Zhang, X. A comparative analysis of China's regional energy and emission performance: Which is the better way to deal with undesirable outputs? Energy Policy 2012, 46, 574-584. [CrossRef]

36. Zhou, P.; Wang, $\mathrm{H}$. Energy and $\mathrm{CO}_{2}$ emission performance in electricity generation: A non-radial directional distance function approach. Eur. J. Oper. Res. 2012, 221, 625-635. [CrossRef]

37. Zhou, P.; Poh, K.L.; Ang, B.W. A non-radial DEA approach to measuring environmental performance. Eur. J. Oper. Res. 2007, 178, 1-9. [CrossRef]

38. Vlontzos, G.; Niavis, S.; Manos, B. A DEA approach for estimating the agricultural energy and environmental efficiency of EU countries. Renew. Sustain. Energy Rev. 2014, 40, 91-96. [CrossRef]

39. Meng, F.; Su, B.; Thomson, E.; Zhou, D.; Zhou, P. Measuring China's regional energy and carbon emission efficiency with DEA models: A survey. Appl. Energy 2016, 183, 1-21. [CrossRef]

40. Geng, Z.Q.; Dong, J.G.; Han, Y.M.; Zhu, Q.X. Energy and environment efficiency analysis based on an improved environment DEA cross-model: Case study of complex chemical processes. Appl. Energy 2017, 205, 465-476. [CrossRef]

41. Wang, J.; Zhao, T. Regional energy-environmental performance and investment strategy for China's non-ferrous metals industry: A non-radial DEA based analysis. J. Clean. Prod. 2016, 163, 187-201. [CrossRef]

42. Perez, K.; González-Araya, M.C.; Iriarte, A. Energy and GHG emission efficiency in the Chilean manufacturing industry: Sectoral and regional analysis by DEA and Malmquist indexes. Energy Econ. 2017, 66, 290-302. [CrossRef]

43. Satterthwaite, D. Cities' contribution to global warming: Notes on the allocation of greenhouse gas emissions. Environ. Urban. 2008, 20, 539-550. [CrossRef]

44. Harris, P.G.; Chow, A.S.Y.; Symons, J. Greenhouse gas emissions from cities and regions: International implications revealed by Hong Kong. Energy Policy 2012, 44, 416-424. [CrossRef] 
45. Li, X.G.; Yang, J.; Liu, X.J. Analysis of Beijing's environmental efficiency and related factors using a DEA model that considers undesirable outputs. Math. Comput. Model. 2013, 58, 956-960. [CrossRef]

46. Yuan, P.; Cheng, S.; Sun, J.; Liang, W. Measuring the environmental efficiency of the Chinese industrial sector: A directional distance function approach. Math. Comput. Model. 2013, 58, 936-947. [CrossRef]

47. Wang, Q.; Zhao, Z.; Shen, N.; Liu, T. Have Chinese cities achieved the win-win between environmental protection and economic development? From the perspective of environmental efficiency. Ecol. Indic. 2015, 51, 151-158. [CrossRef]

48. Zhou, D.Q.; Wang, Q.; Su, B.; Zhou, P.; Yao, L.X. Industrial energy conservation and emission reduction performance in China: A city-level nonparametric analysis. Appl. Energy 2016, 166, 201-209. [CrossRef]

49. Guo, J.; Zhu, D.; Wu, X.; Yan, Y. Study on Environment Performance Evaluation and Regional Differences of Strictly-Environmental-Monitored Cities in China. Sustainability 2017, 9, 2094. [CrossRef]

50. Färe, R.; Grosskopf, S. Directional distance functions and slacks-based measures of efficiency. Eur. J. Oper. Res. 2010, 200, 320-322. [CrossRef]

51. Pastor, J.T.; Asmild, M.; Lovell, C.A.K. The biennial Malmquist productivity change index. Soc. Econ. Plan. Sci. 2011, 45, 10-15. [CrossRef]

52. Jenks, G.F. The Data Model Concept in Statistical Mapping. Int. Yearb. Cartogr. 1967, 7, 186-190.

53. Picazotadeo, A.J.; Castillo, J.; Beltránesteve, M. A Dynamic Approach to Measuring Ecological-Economic Performance with Directional Distance Functions: Greenhouse Gas Emissions in the European Union; Working Papers1304; Department of Applied Economics II, Universidad de Valencia: València, Spain, 2013.

54. Chambers, R.G.; Chung, Y.; Färe, R. Benefit and distance functions. J. Econ. Theory 1995, 70, 407-419. [CrossRef]

55. Wang, H.; Zhou, P.; Zhou, D.Q. Scenario-based energy efficiency and productivity in China: A non-radial directional distance function analysis. Energy Econ. 2013, 40, 795-803. [CrossRef]

56. Getis, A.; Ord, J.K. The analysis of spatial association by use of distance statistics. Geogra. Anal. 1992, 24, 189-206. [CrossRef]

57. Brunsdon, C.; Fotheringham, A.S.; Charlton, M.E. Geographically weighted regression: A method for exploring spatial nonstationarity. Geogr. Anal. 1996, 28, 281-298. [CrossRef]

58. Fotheringham, A.S.; Brunsdon, C.; Charlton, M. Geographically weighted regression: The analysis of spatially varying relationships. Am. J. Agric. Econ. 2004, 86, 554-556.

59. Brunsdon, C.; Fotheringham, A.S.; Charlton, M. Geographically weighted summary statistics-A framework for localised exploratory data analysis. Comput. Environ. Urban Syst. 2002, 26, 501-524. [CrossRef]

60. National Bureau of Statistics of the People's Republic of China. The China City Statistical Yearbook 2011-2015; National Bureau of Statistics of the People's Republic of China: Beijing, China, 2011-2015.

61. National Bureau of Statistics of the People's Republic of China. The China Provincial Statistical Yearbook 2011-2015; National Bureau of Statistics of the People's Republic of China: Beijing, China, 2011-2015. Available online: http:/ / www.stats.gov.cn/tjsj/ndsj/ (accessed on 28 June 2018).

62. Quah, D. Empirical cross-section dynamics in economic growth. Eur. Econ. Rev. 1992, 37, 426-434. [CrossRef]

63. Quah, D. Empirics for economic growth and convergence. Eur. Econ. Rev. 1996, 40, 1353-1375. [CrossRef]

64. Quah, D.T. Empirics for growth and distribution: Stratification, polarization, and convergence clubs. J. Econ. Growth 1997, 2, 27-59. [CrossRef]

65. Meng, F.Y.; Fan, L.W.; Zhou, P.; Zhou, D.Q. Measuring environmental performance in China's industrial sectors with non-radial DEA. Math. Comput. Model. 2013, 58, 1047-1056. [CrossRef]

66. Deng, L.J.; Zhang, P.Y.; Ping, L.I. Equilibrium of population and economic development in the top ten urban agglomerations in China. J. Grad. Sch. Chin. Acad. Sci. 2010, 27, 154-162. (In Chinese)

67. Zeng, P.; Chen, F. Empirical research of "energy-environment-economy" comprehensive accounting system of the top ten urban agglomerations in china. Forum Sci. Technol. China 2012, 29, 62-66. (In Chinese)

68. Peng, L.; Zhang, Y.; Wang, Y.; Zeng, X.; Peng, N.; Yu, A. Energy efficiency and influencing factor analysis in the overall Chinese textile industry. Energy 2015, 93, 1222-1229. [CrossRef]

69. Fan, Y.; Bai, B.; Qi, Q.; Peng, K.; Yue, Z.; Jing, G. Study on eco-efficiency of industrial parks in China based on data envelopment analysis. J. Environ. Manag. 2017, 192, 107-115. [CrossRef] [PubMed]

70. Su, B.; Zhan, M.; Zhai, J.; Wang, Y.; Fischer, T. Spatio-temporal variation of haze days and atmospheric circulation pattern in China (1961-2013). Quat. Int. 2015, 380, 14-21. [CrossRef] 
71. Zhang, J.; Chen, J.; Xia, X.; Che, H.; Fan, X.; Xie, Y.; Han, Z.; Chen, H.; Lu, D. Heavy aerosol loading over the Bohai Bay as revealed by ground and satellite remote sensing. Atmos. Environ. 2015, 124, 252-261. [CrossRef]

72. Zhou, M.; Zhang, Y.; Han, Y.; Wu, J.; Du, X.; Xu, H.; Feng, Y.; Han, S. Spatial and temporal characteristics of PM2.5 acidity during autumn in marine and coastal area of Bohai Sea, China, based on two-site contrast. Atmos. Res. 2018, 202, 196-204. [CrossRef]

73. He, C.; Huang, Z.; Ye, X. Spatial heterogeneity of economic development and industrial pollution in urban China. Stoch. Environ. Res. Risk Assess. 2014, 28, 767-781. [CrossRef]

74. Hu, Z.; Miao, J.; Miao, C. Agglomeration characteristics of industrial pollution and their influencing factors on the scale of cities in China. Dili Yanjiu (Geogr. Res.) 2016, 35, 1470-1482. (In Chinese)

2018 by the authors. Licensee MDPI, Basel, Switzerland. This article is an open access article distributed under the terms and conditions of the Creative Commons Attribution (CC BY) license (http://creativecommons.org/licenses/by/4.0/). 